\title{
Global simulations of nitrate and ammonium aerosols and their radiative effects
}

\author{
L. Xu and J. E. Penner \\ Department of Atmospheric, Oceanic and Space Science, University of Michigan, Ann Arbor, Michigan, USA
}

Correspondence to: L. Xu (lixum@umich.edu)

Received: 26 March 2012 - Published in Atmos. Chem. Phys. Discuss.: 19 April 2012

Revised: 14 September 2012 - Accepted: 24 September 2012 - Published: 22 October 2012

\begin{abstract}
We examine the formation of nitrate and ammonium on five types of externally mixed pre-existing aerosols using the hybrid dynamic method in a global chemistry transport model. The model developed here predicts a similar spatial pattern of total aerosol nitrate and ammonium to that of several pioneering studies, but separates the effects of nitrate and ammonium on pure sulfate, biomass burning, fossil fuel, dust and sea salt aerosols. Nitrate and ammonium boost the scattering efficiency of sulfate and organic matter but lower the extinction of sea salt particles since the hygroscopicity of a mixed nitrate-ammonium-sea salt particle is less than that of pure sea salt. The direct anthropogenic forcing of particulate nitrate and ammonium at the top of the atmosphere (TOA) is estimated to be $-0.12 \mathrm{~W} \mathrm{~m}^{-2}$. Nitrate, ammonium and nitric acid gas also affect aerosol activation and the reflectivity of clouds. The first aerosol indirect forcing by anthropogenic nitrate (gas plus aerosol) and ammonium is estimated to be $-0.09 \mathrm{~W} \mathrm{~m}^{-2}$ at the TOA, almost all of which is due to condensation of nitric acid gas onto growing droplets $\left(-0.08 \mathrm{~W} \mathrm{~m}^{-2}\right)$.
\end{abstract}

\section{Introduction}

Aerosols, especially those from anthropogenic sources, play an important role in changing the Earth's climate. Substantial progress has been made towards understanding how aerosols, such as sulfate, carbonaceous particles, mineral dust and sea salt, can impact the Earth's climate (Penner et al., 2001; Textor et al., 2006; Forster et al., 2007). However, little has been done to quantify the direct and indirect effects of aerosol nitrate and ammonium in spite of the fact that nitrate and ammonium are known to be significant anthropogenic sources of aerosols (Intergovernmental Panel on Climate Change (IPCC), 1994; van Dorland et al., 1997; Adams et al., 1999). A limited number of global models have been used to predict nitrate and ammonium aerosol concentrations (Adams et al., 1999; Metzger et al., 2002; Liao et al., 2003; Rodriguez and Dabdub, 2004; Bauer et al., 2007; Feng and Penner, 2007; Pringle et al., 2010) and their direct radiative effects (van Dorland et al., 1997; Adams et al., 2001; Jacobson, 2001; Liao et al., 2004; Liao and Seinfeld 2005; Bauer et al., 2007; Myhre et al., 2009), but no one has evaluated their indirect forcing. Most global aerosol models included in the AeroCom exercise exclude ammonium and nitrate aerosols (Schulz et al., 2006; Textor et al., 2006; Kinne et al., 2006), and, of those that do, most treat these aerosols in thermodynamic equilibrium, which, for global average conditions, overestimates the portion in coarse aerosols (Feng and Penner, 2007). Major nitrate salts (e.g. ammonium nitrate, sodium nitrate) have lower deliquescence relative humidity $(\mathrm{DRH})$ than their corresponding sulfate salts (e.g. ammonium sulfate, sodium sulfate) and are highly hygroscopic. This normally would be expected to increase aerosol scattering properties and increase both their direct and indirect radiative forcing. The Fourth Assessment Report (i.e. AR4) from the IPCC (Forster et al., 2007) estimates the direct radiative forcing for nitrate to be $-0.10 \pm 0.10 \mathrm{~W} \mathrm{~m}^{-2}$ at the top of atmosphere (TOA). However, the relatively small number of studies is not sufficient to accurately characterize the magnitude and the uncertainties in the direct radiative forcing associated with aerosol nitrate (Forster et al., 2007). Studies (Adams et al., 2001; Liao et al., 2006; Liao and Seinfeld, 2005) using global models have also suggested that the decreased radiative forcing of sulfate aerosols due to their reduced emissions in the future could be partially offset by 
increases in the radiative forcing of nitrate aerosols. Reduction of sulfate in aerosols results in an increase of $\mathrm{NH}_{3}$ in the atmosphere, which allows a larger formation of ammonium nitrate.

As noted above, none of the existing studies has estimated the indirect forcing by ammonium and nitrate aerosols. Furthermore, a number of studies (Kulmala et al., 1993, 1998; Goodman et al., 2000) show that the condensation of nitric acid onto growing cloud droplets contributes soluble material to the droplet and enhances their water uptake and growth, leading to increased droplet number concentrations. Therefore, a full consideration of both $\mathrm{HNO}_{3}(\mathrm{~g})$ and aerosol ammonium and nitrate is needed to properly estimate indirect forcing by aerosols and $\mathrm{HNO}_{3}$ gas.

The formation of nitrate aerosols strongly depends on the availability of its precursor gases and on the ambient conditions. Nitrate aerosols form if sulfate aerosols are irreversibly neutralized and atmospheric ammonia is in excess. Nitrate is predominantly present in the submicron mode at continental sites (ten Brink et al., 1997; Heintzenberg et al., 1998; Putaud et al., 2003) in the form of ammonium nitrate $\left(\mathrm{NH}_{4} \mathrm{NO}_{3}\right)$. Nitrate aerosols have been found to be at least as important as sulfate in some regions of Europe (ten Brink et al., 1996; Schaap et al., 2004) and some urban areas (Malm et al., 2004). Nitrate is internally mixed with sulfate, ammonium, elemental and organic carbon in western Europe (Dall'Osto et al., 2009) and in the Amazon basin (Trebs et al., 2005). However, aerosol nitrate is not just associated with ammonium in the accumulation mode. Coarse mode aerosol nitrate can be produced by adsorption of nitric acid on sea salt particles (Savoie and Prospero, 1982) and soil particles (Wolff, 1984). Lefer and Talbot (2001) found that $86 \%$ of nitrate mass was associated with water-soluble super-micron soilderived $\mathrm{Ca}^{2+}$ in an acid environment. Other metal species like $\mathrm{Mg}^{2+}, \mathrm{Na}^{+}$and $\mathrm{K}^{+}$can also be associated with nitrate. In addition, aerosol nitrate is formed through heterogeneous reactions of nitrogen radicals such as gaseous $\mathrm{NO}_{3}, \mathrm{~N}_{2} \mathrm{O}_{5}$ and $\mathrm{HNO}_{3}$ dissolved into wet aerosol (Ehhalt and Drummond, 1982; Parrish et al., 1986; Li et al., 1993). Ammonium helps to retain nitrate in the aerosol phase by neutralizing the aerosol acidity during heterogeneous formation processes (Adams et al., 1999). Liao and Seinfeld (2005) demonstrate that the heterogeneous chemistry reactions on particles can increase the direct radiative forcing due to nitrate by $25 \%$.

The partitioning of nitrate and ammonium between the gas and aerosol phases has been done using three different approaches. The first approach assumes instantaneous chemical and thermodynamic equilibrium (Pilinis and Seinfeld, 1987; Russell et al., 1988; Binkowski and Shankar, 1995; Lurmann et al., 1997) between the gas and aerosol phase (hereafter referred to as EQ). Instantaneous thermodynamic equilibrium may be assumed for the fine mode aerosols (particle diameter less than $1 \mu \mathrm{m}$ ) since small particles achieve equilibrium with the gas phase within a few minutes (Wexler and Seinfeld, 1990; Dassios and Pandis, 1999). However, assuming ther- modynamic equilibrium between the gas and aerosol phase is not likely to be valid for coarse particles, such as sea salt and mineral dust because it takes from several hours to up to a week to reach equilibrium (Meng and Seinfeld, 1996; Seinfeld and Pandis, 1998) and this time is longer than the time step typically used in chemical transport models (e.g. about $1 \mathrm{~h}$ ). Observations also show that gas phase concentrations and coarse aerosol particles are not in equilibrium (John et al., 1989). A more accurate representation of the partitioning of semi-volatile species called the "dynamic method" (hereafter referred to as DYN) has been developed (Meng and Seinfeld, 1996; Meng et al., 1998; Jacobson et al., 1996; Jacobson, 1997a, b; Sun and Wexler, 1998a, b; Pilinis et al., 2000). In this approach, a fully dynamic mass transfer calculation is applied to each aerosol size bin. Although the dynamic method is most accurate, its use in large-scale air quality models as well as global chemical transport models has been limited due to its high computation cost. The hybrid dynamic method (hereafter referred to as HDYN) was proposed by Capaldo et al. (2000). In this method, the equilibrium method is employed to determine the composition of aerosol particles with diameters less than a threshold diameter (around $1 \mu \mathrm{m}$ ) while the dynamic method developed by Pilinis et al. (2000) is used to calculate the mass transferlimited concentrations in larger particles.

Here, we apply the hybrid dynamic method, first applied in a global model by Feng and Penner (2007, hereafter referred to as FP07), which follows the methods outlined in Capaldo et al. (2000) to calculate the burden of nitrate and ammonium in aerosols. FP07 presented the differences between the predicted nitrate and ammonium in aerosols using the HDYN method and several other methods. Most importantly, they found that the thermodynamic equilibrium assumption underestimates the fine-mode nitrate aerosol burden by $25 \%$. Nitrate and ammonium can also be approximated using a first-order removal approximation based on uptake coefficients. FP07 found that this method overestimates both fine and coarse mode nitrate aerosols, while a simplified form of HDYN (Liao et al., 2003, 2004) overestimates the coarse mode nitrate. These differences would be expected to lead to significant differences in the predicted forcing from nitrate and ammonium.

We updated the FP07 global simulation of nitrate and ammonium aerosols based on the HDYN method but also account for the dynamics of sulfate aerosol and its interaction with non-sulfate aerosol components (Herzog et al., 2004; Liu et al., 2005; Wang et al., 2009). FP07 only simulated aerosol mass and so did not account for the nucleation of new sulfate aerosols and their growth as well as the coating by sulfate on other aerosol types. Since aerosol nitrate is only allowed to form after sulfate is fully neutralized, an accurate representation of sulfate is key to determining the amount of aerosol nitrate that can form.

The three-dimensional global aerosol and chemistry transport model used in this study is described in the Sect. 2 . 
Section 3 presents the present-day global distribution of predicted sulfate, nitric acid and nitrate, ammonia and ammonium. In addition, the global budgets of gaseous nitric acid and nitrate as well as ammonia and ammonium are discussed. The comparisons of aerosol concentrations (i.e. sulfate, nitrate and ammonium) with ground-based observations are also included in this section. The calculated aerosol optical properties are presented in Sect. 4, and estimates of direct and indirect radiative forcing of nitrate and ammonium as well as their anthropogenic contribution are in Sect. 5. The summary and conclusions are presented in Sect. 6.

\section{Model description}

\subsection{Global aerosol and chemistry transport model}

We used the version of the IMPACT global aerosol and chemistry model that treats the microphysics of sulfate aerosol (i.e. nucleation, condensation of gas phase sulfate, and coagulation) and its interaction with non-sulfate aerosols (Liu et al., 2005; Wang et al., 2009). Similar to FP07, modeled transport was driven by assimilated meteorological fields from the NASA Goddard Data Assimilation Office (DAO) general circulation model (GCM) for the year 1997 with a 6-h time interval. The DAO meteorological fields were interpolated to a 1-h time interval for the tracer advection time step in IMPACT. The spatial resolution of the model was $2^{\circ}$ latitude by $2.5^{\circ}$ longitude in the horizontal with 26 vertical layers ranging from the surface to $2.5 \mathrm{hPa}$. The model uses the flux form semi-Lagrangian (FFSL) advection scheme (Lin and Rood, 1996) while vertical diffusion is based on an implicit scheme described in Walton et al. (1988) using vertical diffusion coefficients provided by the DAO meteorological fields.

We used two modes to treat the mass and number of sulfate aerosol and its microphysical interactions (Herzog et al., 2004; Liu et al., 2005): a nucleation/Aitken mode $(r<0.05 \mu \mathrm{m})$ and an accumulation mode $(r>0.05 \mu \mathrm{m})$. Nonsulfate aerosols are assumed to follow prescribed background size distributions based on observations (Table 1). Carbonaceous aerosols (OM and $\mathrm{BC}$ ) are represented by a single submicron size bin but separate tracers are carried for biomass burning, natural and fossil fuel particles based on their source origins. Sea salt and mineral dust aerosols are represented in four bins with radii varying from $0.05-0.63 \mu \mathrm{m}, 0.63-$ $1.26 \mu \mathrm{m}, 1.26-2.5 \mu \mathrm{m}$, and $2.5-10 \mu \mathrm{m}$ to account for varying removal rates and thermodynamics. These size distributions are also used for the radiative properties of the separate size bins as well as the varying cloud condensation nuclei activation spectrum.

Binary homogeneous nucleation of $\mathrm{H}_{2} \mathrm{SO}_{4}$ (gas) is used to determine the nucleation of sulfate aerosols (Vehkamäki et al., 2002). In addition, $2 \%$ of the anthropogenic sulfur emissions are assumed to be emitted as primary aerosols
Table 1. Size distribution parameters for non-sulfate aerosols.

\begin{tabular}{lrrr}
\hline Aerosol Component & $N_{i}^{\mathrm{a}}$ & $r_{i}, \mu \mathrm{m}$ & $\sigma_{i}$ \\
\hline Fossil fuel OM/BC & 0.428571 & 0.005 & 1.5 \\
& 0.571428 & 0.08 & 1.7 \\
& $1 . \times 10^{-6}$ & 2.5 & 1.65 \\
\hline Biomass OM/BC and natural OM $^{\mathrm{c}}$ & 0.9987 & 0.0774 & 1.402 \\
& $1.306 \times 10^{-3}$ & 0.3360 & 1.383 \\
& $2.830 \times 10^{-3}$ & 0.9577 & 1.425 \\
\hline Sea salt $^{\mathrm{d}}$ & 0.965 & 0.035 & 1.92 \\
& 0.035 & 0.41 & 1.70 \\
\hline Dust $^{\mathrm{e}}$ & 0.854240 & 0.05 & 1.65 \\
& 0.145687 & 0.27 & 2.67 \\
& $7.3 \times 10^{-5}$ & 4.0 & 2.40 \\
\hline
\end{tabular}

${ }^{\text {a }} \mathrm{N}_{i}$ is normalized fraction by total number concentration in a given size range and is dimensionless.

b Penner et al. (1998). Note although the size distribution of OM/BC for pollution is adopted from an observation from a Hardiman forest fire (Radke et al., 1988), the median diameter of the mass distribution (i.e. $0.16 \mu \mathrm{m}$ ) is close to that measured $(0.18 \mu \mathrm{m})$ by Schwarz et al. (2010).

c Anderson et al. (1996).

d Quinn and Coffman (1998).

e d'Almeida et al. (1991).

with a specified size distribution to mimic the effects of sub-grid scale processes leading to aerosol nucleation. The hydrophilic and hydrophobic properties and corresponding scavenging efficiency of non-sulfate aerosols are determined by the amount of sulfate coating that is produced through coagulation and condensation and the amount of nitrate and ammonium on each aerosol type. Condensational growth is kinetically limited by the diffusion of sulfuric acid gas to the particle surface. Coagulation is allowed to occur between sulfate particles of the same size and between particles of different sizes as well as with non-sulfate particles. Sulfate produced within cloud droplets is equally distributed among the hygroscopic aerosol particles that are larger than $0.05 \mu \mathrm{m}$ in radius.

Dry deposition rates for gaseous species are calculated based on the work of Jacob and Wofsy (1990), Wesely (1989) and Walcek et al. (1996). Dry deposition of aerosol particles uses a resistance-in-series parameterization following Zhang et al. (2001). Gravitational settling is also taken into account. Wet deposition is calculated by using the wet scavenging model described in Mari et al. (2000) and Liu et al. (2001). Two types of scavenging are included: (1) scavenging in wet convective updrafts, and (2) first-order rainout and washout in precipitating columns. For scavenging in convective updrafts, the fraction of tracer scavenged depends on the rate constant for conversion of cloud condensate to precipitation (assumed to be $0.005 \mathrm{~s}^{-1}$ ) as well as the fraction of tracer present in the condensate $f_{i}$ (i.e. the scavenging efficiency). The fraction of highly soluble gaseous species such as $\mathrm{HNO}_{3}(\mathrm{~g})$ and $\mathrm{H}_{2} \mathrm{SO}_{4}(\mathrm{~g})$ in the cloud condensate phase is assumed to be $100 \%$ while scavenging efficiencies of less soluble gaseous species are calculated based on their 
Henry's law coefficients. Scavenging efficiencies of aerosol species are either prescribed to be constant for pure sulfate aerosol and sea salt with $f_{i}=1$ or (for BC/OM and mineral dust) are calculated based on the amount of sulfate, ammonium and nitrate associated with the particles $\left(0<f_{i}<1\right)$. For the latter effects, we updated the scavenging efficiencies for sulfate-coated aerosols described in Liu et al. (2005), to account for the amount of coverage by internally mixed sulfate, ammonium and nitrate molecules. Thus, the fractional area coverage of a single non-sulfate-ammonium-nitrate particle surface by internally mixed sulfate, ammonium and nitrate molecules (e.g. for carbonaceous aerosols) was calculated from

$x_{\mathrm{BC}+\mathrm{OM}}^{\mathrm{SO}_{4}+\mathrm{NO}_{3}+\mathrm{NH}_{4}}=\frac{r_{\mathrm{avg}}^{2} N_{\mathrm{avg}}}{4\left(r_{\mathrm{BC}+\mathrm{OM}}+r_{\mathrm{avg}}\right)^{2}}$,

where $r_{\mathrm{BC}+\mathrm{OM}}$ is the mass-weighted average radius for carbonaceous particles; $r_{\text {avg }}$ is the average radius of internally mixed sulfate, ammonium and nitrate molecules; and $N_{\text {avg }}$ is the total number of molecules of internally mixed sulfate, ammonium and nitrate on the particle surface. Following Liu et al. (2005), when $f_{\mathrm{BC}+\mathrm{OM}}^{\mathrm{SO}_{4}+\mathrm{NO}_{3}+\mathrm{NH}_{4}}=10$ (layers), the particle becomes fully hygroscopic so that $f_{i}=1$ and is linearly interpolated between 0 and 1 for less than 10 monolayers. In addition, wet scavenging efficiencies for accumulation mode sulfate and sea salt mixed with nitrate and ammonium are assumed to be 1.0 while the nucleation/Aitken mode aerosols are only scavenged as a result of their Brownian coagulation with cloud droplets.

Table 2 summarizes the emissions used for present day (PD) and pre-industrial (PI) scenarios. Ammonia emissions for the present-day were taken from the global inventory of Bouwman et al. (1997). The total ammonia source specified in this inventory is estimated to be $53.6 \mathrm{Tg} \mathrm{N}$ per year and Table 2 lists the contributions of each source type to the total emission. Among nine sources, domestic animals contribute the largest fraction, $34 \%$, followed by synthetic fertilizers, oceans, biomass burning, soils under natural vegetation, wild animals and other sources. The ammonia emissions for pre-industrial conditions include the emission sources from oceans, soils under vegetation and wild animals. We assume that all other sources have anthropogenic origins and were near zero in the year 1850 . The total ammonia emission in the PI scenario is $10.7 \mathrm{Tg} \mathrm{N}$ per year.

The emissions of $\mathrm{NO}_{\mathrm{x}}$ from industrial activities, fossil fuel combustion as well as soil process are from van Aardenne et al. (2001) for 1990, while those from biomass burning and lightning are based on the year 1990 (Ito et al., 2007, 2009). The largest fraction of $\mathrm{NO}_{\mathrm{x}}$ emissions are associated with industrial activity and fossil fuel combustion, $22.7 \mathrm{Tg} \mathrm{N}$ per year, out of a total $\mathrm{NO}_{\mathrm{x}}$ emission $41.0 \mathrm{Tg} \mathrm{N}$ per year. The next largest sources are biomass burning, soil processes, lightning and aircraft emissions, in that order. The total $\mathrm{NO}_{\mathrm{x}}$ emission for PI conditions, representative of 1890 , is $11.7 \mathrm{Tg} \mathrm{N}$ per
Table 2. Global annual emission for pre-industrial and present-day scenarios.

\begin{tabular}{|c|c|c|}
\hline \multirow[b]{2}{*}{ Species } & \multicolumn{2}{|c|}{ Scenario } \\
\hline & $\begin{array}{r}\text { Pre-industrial } \\
1850\end{array}$ & $\begin{array}{r}\text { Present-Day } \\
2000\end{array}$ \\
\hline \multicolumn{3}{|l|}{$\mathrm{NH}_{3}, \mathrm{Tg} \mathrm{N} \mathrm{yr}^{-1}$} \\
\hline Domesticated animals & - & 21.6 \\
\hline Synthetic fertilizers & - & 9.0 \\
\hline Oceans & 8.2 & 8.2 \\
\hline Biomass burning & - & 5.9 \\
\hline Crops & - & 3.6 \\
\hline Humans & - & 2.6 \\
\hline Soils under natural vegetation & 2.4 & 2.4 \\
\hline Wild animals & 0.1 & 0.1 \\
\hline Others & - & 0.3 \\
\hline Total $^{\mathrm{a}}$ & 10.7 & 53.6 \\
\hline \multicolumn{3}{|l|}{$\mathrm{NO}_{\mathrm{x}}, \mathrm{Tg} \mathrm{N} \mathrm{yr}{ }^{-1}$} \\
\hline Industrial activities/Fossil fuel combustion & $1.0^{\mathrm{b}}$ & $22.7^{\mathrm{b}}$ \\
\hline Biomass burning & $4.8^{\mathrm{c}}$ & $9.3^{\mathrm{c}}$ \\
\hline Soil processes & $2.9^{\mathrm{b}}$ & $5.5^{\mathrm{b}}$ \\
\hline Lightning & $3.0^{\mathrm{d}}$ & $3.0^{\mathrm{d}}$ \\
\hline Aircraft & - & 0.5 \\
\hline Total & 11.7 & 41.0 \\
\hline \multicolumn{3}{|l|}{$\mathrm{SO}_{2}, \mathrm{Tg} \mathrm{S} \mathrm{yr}^{-1}$} \\
\hline Anthropogenic emission & 1.5 & 60.1 \\
\hline Volcanic emission & 4.8 & 4.8 \\
\hline Biomass burning & - & - \\
\hline DMS oxidation & 34.6 & 34.6 \\
\hline Total & 40.9 & 99.5 \\
\hline \multicolumn{3}{|l|}{ DMS, $\mathrm{Tg} \mathrm{S} \mathrm{yr}^{-1}$} \\
\hline Oceanic source & 26.1 & 26.1 \\
\hline \multicolumn{3}{|l|}{$\mathrm{OM}, \mathrm{Tg} \mathrm{yr}^{-1}$} \\
\hline Fossil fuel emission & 5.1 & 15.8 \\
\hline Biomass burning emission & 17.8 & 47.4 \\
\hline Photochemistry from terpenes & 14.5 & 14.5 \\
\hline Total & 37.4 & 77.6 \\
\hline \multicolumn{3}{|l|}{$\mathrm{BC}, \mathrm{Tg} \mathrm{yr}^{-1}$} \\
\hline Fossil/biofuel fuel emission & 0.8 & 5.8 \\
\hline Biomass burning emission & 1.7 & 4.7 \\
\hline Total & 2.5 & 10.5 \\
\hline
\end{tabular}

a Bouwman et al. (1997); ${ }^{b}$ From van Aardenne et al. (2001); ${ }^{\mathrm{c}}$ From Ito et al. (2007); d From Ito et al. (2009).

year which is dominated by biomass burning and lightning sources.

Anthropogenic sulfur emission as well as volcanic $\mathrm{SO}_{2}$ emission, marine DMS fluxes, $\mathrm{OM}$ and $\mathrm{BC}$ fluxes are same as that used in Wang et al. (2009). Sea salt emissions in the model were estimated off-line and provided by Gong et al. (1997). The algorithm of Monahan et al. (1986) was used in order to interpolate the total mass flux into our 4 size bins (0.05-0.63 $\mu \mathrm{m}, 0.63-1.26 \mu \mathrm{m}, 1.26-2.5 \mu \mathrm{m}$, and 2.5-10 $\mu \mathrm{m})$. The total sea salt emissions are $3768 \mathrm{Tg} \mathrm{yr}^{-1}$. The dust emission fluxes at each $6 \mathrm{~h}$ interval were from Ginoux et al. (2001) based on observed $10 \mathrm{~m}$ wind speed and soil wetness. The 
Table 3. Constituent composition simulated for each aerosol type.

\begin{tabular}{ll}
\hline Constituent composition & Size bin(s) applied \\
\hline Pure sulfate with $\mathrm{NO}_{3}^{-}, \mathrm{NH}_{4}^{+}$and $\mathrm{H}_{2} \mathrm{O}(\mathrm{aq})$ & $\mathrm{Bin} 1(D<1.25 \mu \mathrm{m})$ \\
$\mathrm{FF} \mathrm{OM} / \mathrm{BC}$ and associated $\mathrm{SO}_{4}^{2-}, \mathrm{NO}_{3}^{-}, \mathrm{NH}_{4}^{+}$and $\mathrm{H}_{2} \mathrm{O}(\mathrm{aq})$ & $\mathrm{Bin} 1(D<1.25 \mu \mathrm{m})$ \\
$\mathrm{BB} \mathrm{OM} / \mathrm{BC}$ and associated $\mathrm{SO}_{4}^{2-}, \mathrm{NO}_{3}^{-}, \mathrm{NH}_{4}^{+}$and $\mathrm{H}_{2} \mathrm{O}(\mathrm{aq})$ & $\mathrm{Bin} 1(D<1.25 \mu \mathrm{m})$ \\
Dust and associated $\mathrm{SO}_{4}^{2-}, \mathrm{NO}_{3}^{-}, \mathrm{NH}_{4}^{+}$and $\mathrm{H}_{2} \mathrm{O}(\mathrm{aq})$ & $\mathrm{Bin} 1,2,3,4$ \\
Sea salt and associated $\mathrm{SO}_{4}^{2-}, \mathrm{NO}_{3}^{-}, \mathrm{NH}_{4}^{+}$and $\mathrm{H}_{2} \mathrm{O}(\mathrm{aq})$ & $\mathrm{Bin} 1,2,3,4$ \\
\hline
\end{tabular}

dust emissions fluxes are represented by the same 4 size bins as the sea salt aerosols and are described in detail in Liu et al. (2005). Similar to biomass burning aerosols, mineral dust emissions are uniformly injected in the boundary layer.

The simple nitrogen chemistry treatment described by Feng and Penner (2007) was adopted. This treatment calculates the gas phase concentrations of $\mathrm{NO}, \mathrm{NO}_{2}, \mathrm{NO}_{3}, \mathrm{~N}_{2} \mathrm{O}_{5}$ and $\mathrm{HNO}_{3}$. In the simple chemistry, the three dimensional concentration fields of $\mathrm{OH}$ and $\mathrm{O}_{3}$ are fixed monthly averages, taken from a 1-yr simulation of the chemistry transport model GRANTOUR using the climate model CCM1 meteorological fields (Penner et al., 1994). The diurnal cycle of $\mathrm{OH}$ and $\mathrm{HO}_{2}$ is approximated by scaling the monthly average fields using the cosine of the solar zenith angle. The model was run for four different months (i.e. January, April, July and October) with a 1 month spin-up for each month to obtain an annual average aerosol concentration field.

\subsection{Treatment of nitrate and ammonium}

Following FP07, we used the EQUISOLV II thermodynamic equilibrium model (Jacobson, 1999) to calculate the nitrate and ammonium within aerosols with diameters less than $1.25 \mu \mathrm{m}$ (i.e. bin 1 , hereafter referred to as the fine mode) and solved the mass transfer equations for particles with aerosol diameters larger than $1.25 \mu \mathrm{m}$ (i.e. the 3 larger size bins, hereafter referred to as the coarse mode). The equilibrium assumption is well justified for fine mode aerosols in our global aerosol transport model since a transport time step of one hour is used. Accommodation coefficients of 0.193, 0.092 and 0.1 were used for $\mathrm{HNO}_{3}, \mathrm{NH}_{3}$ and $\mathrm{N}_{2} \mathrm{O}_{5}$ (Feng and Penner, 2007) when solving mass transfer equations.

Although aerosol particles are often found as partially or completely internally mixed with multiple components (Zhang et al., 2003), particles near their sources are generally externally mixed. Therefore, the assumption of a complete internal mixture can distort the predicted particle chemical composition (Kleeman et al., 1997), as well as possibly radiative effects. Whereas FP07 made this assumption of necessity, here nitric acid and ammonia interact with each of the other pre-existing externally mixed aerosol populations for a total of 11 populations, i.e. pure sulfate, sulfate-associated with carbonaceous particles, sea salt and dust (see Table 3), which provides a more realistic representation than fully in- ternally mixed aerosols as in FP07. We apply thermodynamic equilibrium (Jacobson, 1999) for the five aerosols types consecutively (i.e. pure sulfate, carbonaceous aerosols from fossil fuel, carbonaceous aerosols from biomass burning, dust and sea salt) in size bin 1 , followed by solving the mass transfer equations for nitrate and ammonium in the 3 larger size bins $(D>1.25 \mu \mathrm{m})$ for dust and sea salt. Sulfate is first neutralized by ammonia and then nitric acid is allowed to react with ammonia and the other aerosol particles. Changing the reaction order that we used for dust and sea salt changes the nitrate and ammonium concentrations by less than $10 \%$ for high concentrations of both dust and sea salt. In order to eliminate differences introduced by the reaction sequence, we switched the order of the reactions (i.e. by solving the reactions with dust first at odd time steps and with sea salt first at even time steps). While we thought the introduction of externally mixed populations might make an important difference to the burden of nitrate and ammonium, the global average results from this model are similar to those in FP07. Nevertheless, we present the burdens associated with each aerosol field below, since this is the first model that has separately calculated these effects. The disinterested reader can skip to Sect. 4.

\section{Present-day global aerosol concentration fields}

\subsection{Sulfate}

Simulated results for the sulfur model used in this work were presented and compared with observations in Liu et al. (2005). Results presented here are only shown in order to understand the behavior of the other aerosol components. Figure 1 shows the predicted annual averaged mixing ratios (pptv) of pure sulfate and sulfate coated on other aerosol particles at the surface (i.e. the first model level) for the PD scenario. The highest pure sulfate concentrations are mainly located in the industrialized regions of the Northern Hemisphere where they typically exceed $1 \mathrm{ppbv}\left(1 \mu \mathrm{g} \mathrm{m}{ }^{-3} \mathrm{SO}_{4}^{2-}=\right.$ $258 \mathrm{pptv}$ at $298 \mathrm{~K}$ and $1000 \mathrm{mb}$ ). The sulfate associated with other aerosol types is highest near the source regions of the corresponding pre-existing aerosols. 

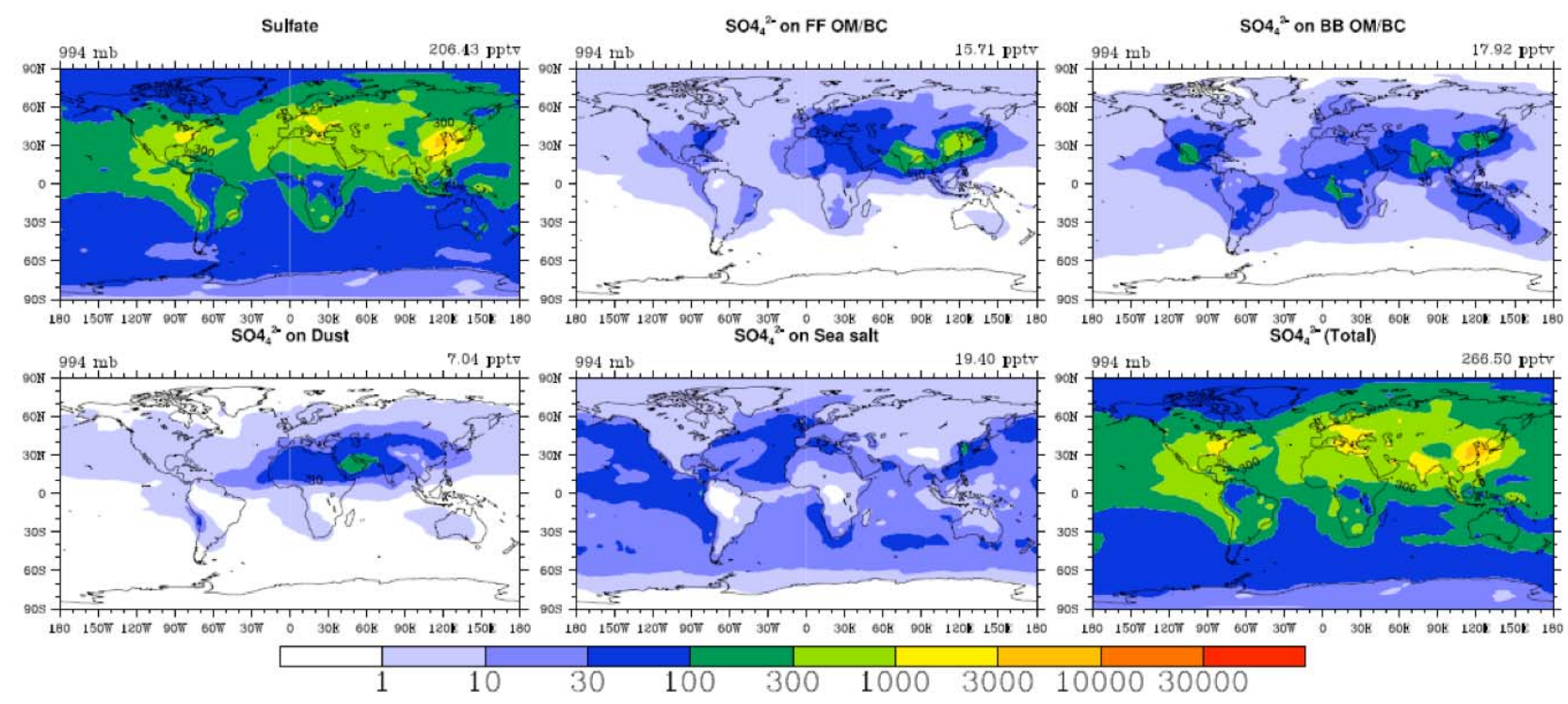

Fig. 1. Predicted annual average mixing ratios (pptv) of pure sulfate and coated sulfate as well as the total sulfate aerosols (bottom right) in the surface layer. The pressure level of the surface layer together with the average mixing ratio for that layer is indicated above each panel.

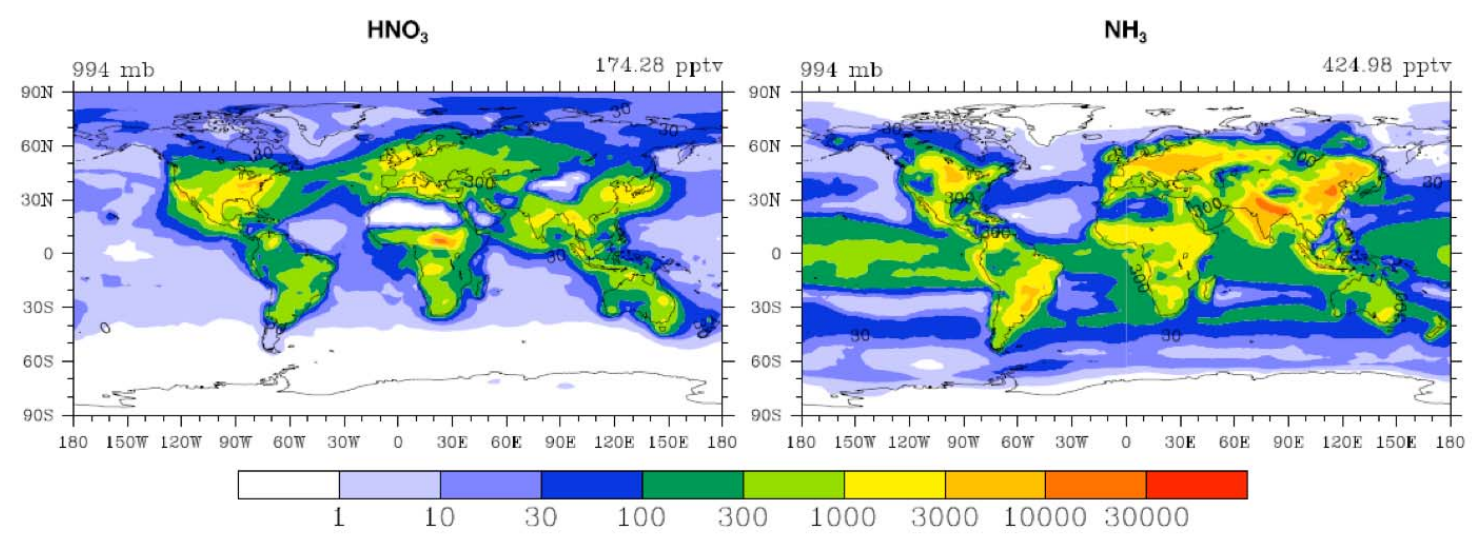

Fig. 2. Predicted annual average mixing ratios (pptv) of gaseous $\mathrm{HNO}_{3}$ (left) and $\mathrm{NH}_{3}$ (right) in the surface layer. The pressure level of the surface layer together with the average mixing ratio for that layer is indicated above each panel.

\subsection{Nitric acid and nitrate}

The predicted annual average gas-phase $\mathrm{HNO}_{3}$ at the surface is given in Fig. 2 (left panel). In general, the $\mathrm{HNO}_{3}$ mixing ratios in the Northern Hemisphere are higher in January than in July because the loss of $\mathrm{HNO}_{3}$ by photolysis and its reaction with $\mathrm{OH}$ is comparably smaller in winter (see FP07) due to weaker sunlight. The winter-summer contrast also applies to its accompanying aerosol component, aerosol nitrate. The predicted $\mathrm{HNO}_{3}$ mixing ratio, generally exceeds $1 \mathrm{ppbv}$ in the industrialized areas of Europe, central and eastern Asia, North America as well as over open biomass burning regions in the tropics. The simulated nitric acid is close to that in the previous study (Feng and Penner, 2007) since similar $\mathrm{NO}_{\mathrm{x}}$ emissions were used as well as the same simple nitro- gen chemistry mechanism. Comparing the nitric acid mixing ratio near surface with two other global model studies (Adams et al., 1999, hereafter A99; Liao et al., 2003, hereafter L03), the nitric acid gas in the present study shares a similar spatial pattern as these two studies though the global annual average nitric acid gas is about $60 \%$ and $36 \%$ lower than A99 and L03, respectively. In addition, the annual average tropospheric burden of nitric acid $(0.30 \mathrm{Tg} \mathrm{N}$, see Table 4) is about a factor of 3 and 2 smaller than that in Bauer et al. (2007) (0.86 Tg N) and Pringle et al. (2010) (0.55 Tg N), respectively.

The predicted present day mixing ratios (pptv) of nitrate aerosols formed on the five types of pre-existing aerosols and total nitrate aerosols at the surface are shown in Fig. 3. The locations of the peaks in the aerosol nitrate mixing ratio are 
Table 4. Global annual budgets of $\mathrm{HNO}_{3}(\mathrm{~g})$ and nitrate $\left(\mathrm{NO}_{3}^{-}\right)$for present-day and pre-industrial scenarios.

\begin{tabular}{|c|c|c|}
\hline & \multicolumn{2}{|c|}{ Scenario } \\
\hline & Present-Day & Pre-industrial \\
\hline \multicolumn{3}{|l|}{$\mathrm{HNO}_{3}(\mathrm{~g})$} \\
\hline Sources $\left(\mathrm{Tg} \mathrm{N}_{\mathrm{yr}}{ }^{-1}\right)$ & 42.30 & 14.72 \\
\hline $\mathrm{NO}_{2}+\mathrm{OH}$ & 24.38 & 11.20 \\
\hline $\mathrm{N}_{2} \mathrm{O}_{5}+$ aerosol & 17.92 & 3.52 \\
\hline Loss $\left(\mathrm{Tg} \mathrm{N} \mathrm{yr}^{-1}\right)$ & 42.30 & 14.72 \\
\hline $\mathrm{HNO}_{3}+\mathrm{OH}$ and $\mathrm{HNO}_{3}+h v$ & 4.31 & 3.39 \\
\hline Loss to nitrate & 15.92 & 4.68 \\
\hline Dry deposition & 7.79 & 2.08 \\
\hline Wet deposition & 14.48 & 4.67 \\
\hline $\operatorname{Burden}(\operatorname{Tg} N)^{\mathrm{a}}$ & 0.30 & 0.15 \\
\hline Above 5 km (\%) & 80.46 & 91.57 \\
\hline In polar $(\%)^{\mathrm{b}}$ & 1.91 & 2.06 \\
\hline Lifetime & 4.76 & 4.80 \\
\hline Removal rate $\left(\right.$ day $\left.^{-1}\right)$ & 0.21 & 0.13 \\
\hline Wet & 0.13 & 0.09 \\
\hline Dry & 0.07 & 0.04 \\
\hline Wet $(\%)$ & 65.00 & 69.11 \\
\hline \multicolumn{3}{|l|}{$\mathrm{NO}_{3}^{-}$} \\
\hline Sources $\left(\mathrm{Tg} \mathrm{N} \mathrm{yr}^{-1}\right)$ & 15.92 & 4.68 \\
\hline Gas-to-aerosol $(D<1.25 \mu \mathrm{m})$ & 8.76 & 2.49 \\
\hline Gas-to-aerosol $(D>1.25 \mu \mathrm{m})$ & 7.16 & 2.19 \\
\hline $\operatorname{Loss}\left(\operatorname{Tg~N~yr}^{-1}\right)$ & 15.92 & 4.48 \\
\hline Dry deposition & 3.96 & 0.72 \\
\hline Wet deposition & 11.96 & 3.96 \\
\hline Burden $(\mathrm{Tg} N)$ & 0.17 & 0.08 \\
\hline On pure sulfate $(\%)$ & 23.17 & 19.96 \\
\hline On carbonaceous aerosols $(\%)$ & 2.10 & 2.18 \\
\hline On dust bins $1-4(\%)$ & $12.28,15.96,27.09,2.52$ & $24.72,15.93,23.70,1.29$ \\
\hline On sea salt bins $1-4(\%)$ & $14.73,1.14,0.84,0.16$ & $11.24,0.53,0.40,0.05$ \\
\hline Fine-mode $(D<1.25 \mu \mathrm{m})$ & 52.29 & 58.10 \\
\hline Coarse-mode $(D>1.25 \mu \mathrm{m})$ & 47.71 & 41.90 \\
\hline Above $5 \mathrm{~km}(\%)$ & 24.43 & 38.37 \\
\hline In polar $(\%)$ & 1.25 & 1.92 \\
\hline Lifetime & 3.92 & 6.26 \\
\hline Removal rate $\left(\right.$ day $\left.^{-1}\right)$ & 0.25 & 0.16 \\
\hline Wet & 0.19 & 0.13 \\
\hline Dry & 0.06 & 0.03 \\
\hline Wet $(\%)$ & 75.37 & 84.39 \\
\hline
\end{tabular}

a The tropospheric $\mathrm{HNO}_{3}$ burden was calculated by the summation of $\mathrm{HNO}_{3}$ concentrations over the model levels below $200 \mathrm{hPa}$ in this work.

b South of $80^{\circ} \mathrm{S}$ and north of $80^{\circ} \mathrm{S}$.

consistent with those from previous studies (Feng and Penner, 2007; Liao et al., 2003; Adams et al., 1999). Note that $1 \mu \mathrm{g} \mathrm{m}^{-3} \mathrm{NO}_{3}^{-}=400 \mathrm{pptv}$ at $298 \mathrm{~K}$ and $1000 \mathrm{mb}$. The nitrate mixing ratios condensed on pure sulfate generally exceed 1 ppbv over eastern United States, Europe, India, and eastern Asia. The nitrate associated with fossil fuel/biofuel OM/BC maximizes in eastern Asia with an average value of about 100 to $300 \mathrm{pptv}$ while that associated with biomass burning aerosols is highest over major burning regions. The location of the peak in the aerosol nitrate predicted on dust and sea salt aerosols occurs over the Sahara desert for dust and over coastal regions close to the continents for sea salt. Most continental areas in the Northern Hemisphere have nitrate mixing ratios exceeding $300 \mathrm{pptv}$. In the Southern Hemisphere, a value as large as this only occurs in highly localized areas such as part of South America, South Africa and Australia. 

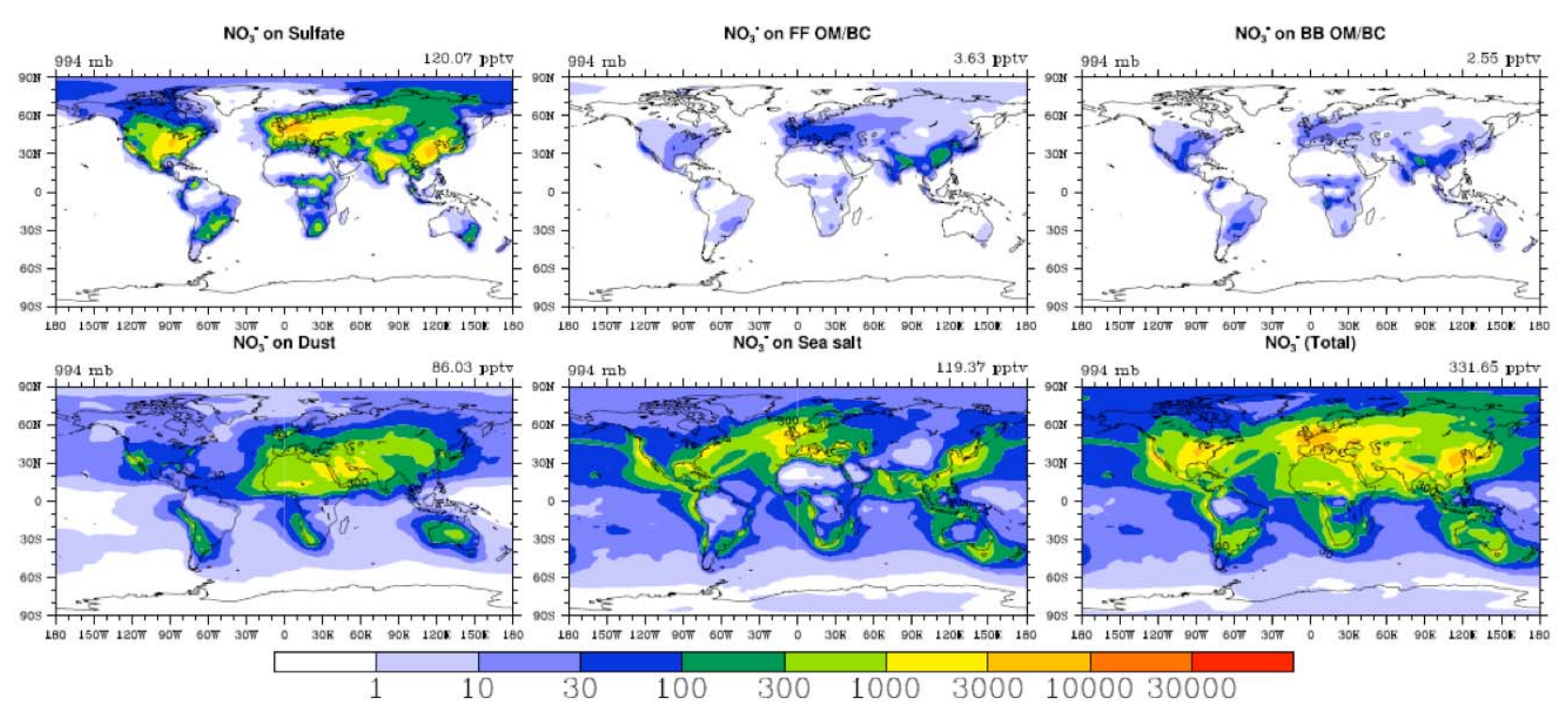

Fig. 3. Predicted annual average mixing ratios (pptv) of nitrate associated with each aerosol type and for total nitrate in aerosols (bottom right) in the surface layer. The pressure level of the surface layer together with the average mixing ratio for that layer is indicated above each panel.
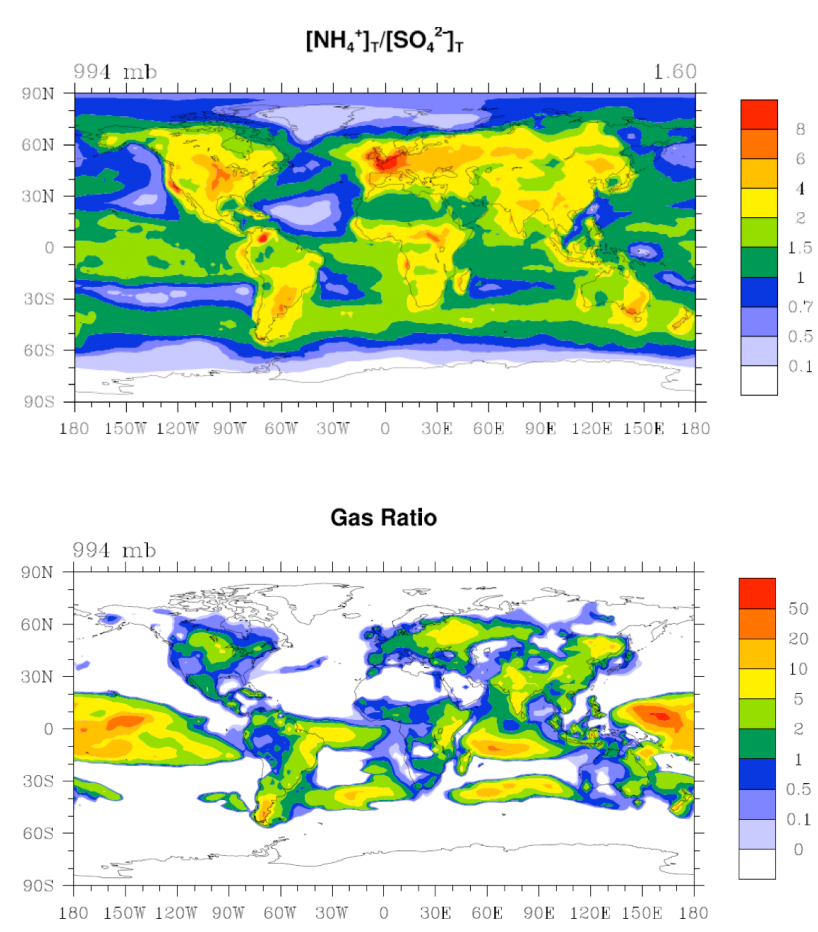

Fig. 4. Annual average molar ratio of total ammonium to total sulfate (top) and gas ratio (bottom) in the the surface layer. See text for the definition of the gas ratio.
Marine mixing ratios of nitrate aerosols are generally in the range of 1-100 pptv except in coastal regions. Zonal average mixing ratios are very similar to those shown by FP07, so are not discussed here.

As noted earlier, the formation of nitrate depends on the abundance of ammonia. The molar ratio of total ammonium to total sulfate (shown in Fig. 4, top panel) is generally larger than 2 over continents and less than 2 over oceans, indicating that the excess ammonia over continents is available to react with nitrate while ammonia is limiting in most ocean areas. Figure 4 (bottom panel) shows annual average gas ratio (Ansari and Pandis, 1998) near the surface. The gas ratio is defined as the free ammonia $\left(\left[\mathrm{NH}_{3}\right]+\left[\mathrm{NH}_{4}^{+}\right]-2 \times\left[\mathrm{SO}_{4}^{2-}\right]\right)$ divided by the total nitrate $\left(\left[\mathrm{HNO}_{3}\right]+\left[\mathrm{NO}_{3}^{-}\right]\right)$expressed in molar concentration units. The gas ratio is useful for indicating which reactant, ammonia or nitric acid, limits the formation of ammonium nitrate. If the gas ratio is greater than 1 , it indicates that nitric acid is limiting. A gas ratio with the value between 0 and 1 indicates that ammonia is limiting even though some ammonia is available for reaction with nitric acid. If the gas ratio is less than 0 , it indicates that that ammonia is significantly limited. Then no free ammonia is available and the formation of ammonium nitrate is not possible because all of the ammonia will preferentially react with sulfate. On an annual average basis, free ammonia exists in most populated areas of the globe. A high gas ratio is also found in Brazil, Patagonia, India as well as the southern Atlantic and Indian oceans. The high gas ratio over oceans is expected in accordance with the ocean sources of ammonia and the absence of $\mathrm{HNO}_{3}$ sources. On the other 
hand, ammonia is limited in remote continental and marine areas.

\subsection{Ammonia and ammonium}

The present day annual average mixing ratios of gas phase ammonia at the surface are shown in Fig. 2 (right panel). The highest surface mixing ratios, in excess of $1 \mathrm{ppbv}$ with some peaks more than $10 \mathrm{ppbv}\left(1 \mu \mathrm{g} \mathrm{m}^{-3}=1457 \mathrm{pptv} \mathrm{NH}_{3}\right.$ at $298 \mathrm{~K}$ and $1000 \mathrm{mb}$ ), are found in China, India, Europe, eastern United States, Brazil and South Africa. Continental mixing ratios exceed 300 pptv everywhere except the Arctic, Sahara, and southwestern Australia. Marine mixing ratios of gas phase ammonia are highest near the equator and over the Southern ocean as a result of high ammonia emissions in that part of the ocean; otherwise, they are less than 100 pptv. Ammonia mixing ratios are negligibly small (less than $1 \mathrm{pptv}$ ) over most of Antarctica. Ammonia surface mixing ratios are mainly determined by both the emissions of ammonia and its uptake by sulfate and nitrate.

The annual average mixing ratios of ammonium aerosols on each aerosol type as well as the total at the surface are shown in Fig. 5. The total ammonium concentrations predicted here are similar to those of Adams et al. (1999) and Feng and Penner (2007), including locations and magnitudes of the peaks. Because ammonium is preferentially associated with sulfate, the peaks in the ammonium mixing ratios are closely tied with those of sulfate. As expected, ammonium on pure sulfate is the largest among the five aerosol types. The highest total ammonium mixing ratios exceed 3 ppbv and are found in industrialized regions, $\left(1 \mu \mathrm{g} \mathrm{m}^{-3}=1377 \mathrm{pptv} \mathrm{NH}_{4}^{+}\right.$ at $298 \mathrm{~K}$ and $1000 \mathrm{mb}$ ). Continental mixing ratios exceed 300 pptv almost everywhere while marine mixing ratios of ammonium are in the range of 100-300 pptv except for remote oceans. The alkaline compounds (i.e. $\mathrm{Ca}^{2+}, \mathrm{Na}^{+}, \mathrm{K}^{+}$, $\mathrm{Mg}^{2+}$ ) in dust and the cation $\mathrm{Na}^{+}$tied to sea salt make it difficult for ammonia to partition into dust and sea salt particles. The anion (e.g. $\mathrm{Cl}^{-}$) in sea salt may be associated with ammonium when both sulfate and nitrate are in poor abundance. Zonal average mixing ratios are very similar to those shown by FP07, so are not discussed here.

\subsection{Comparisons of aerosol concentrations with ground-based measurements}

Aerosol concentrations (sulfate, ammonium and nitrate) are compared with two ground-based measurement data sets, EMEFS and EMEP, representing polluted continental conditions. We adopted the EMEFS (Eulerian Model Evaluation Field Study) data set presented in A99, which includes annual average sulfate, ammonium and nitrate concentrations for 75 sites spread throughout eastern North America. The EMEP (European Monitoring and Evaluation Programme) reported annual averages from 1986 to 2009 in Europe. Following A99 and FP07, the year of 1995 data is taken to facil- itate the comparison of ammonium and nitrate aerosol since the simulated sulfate concentrations most closely match with reported observations. In general, modeled aerosol concentrations for sulfate, ammonium and nitrate agree well with the observed values, similar to the comparison conducted in FP07 and A99. A detailed discussion may be found in FP07 and is not repeated here. The comparison results are presented in Appendix A. We note that as in FP07 and A99, nitrate over North America is overpredicted in the model in comparison with measurements, possibly as a result of evaporation from the filter packs resulting in values that are biased low in the measurements (Adams et al., 1999; Pakkanen et al., 1999), although neglect of the formation of organic nitrates in our simple treatment of gas phase nitrogen chemistry may also play a role (up to $50 \%$ in some areas according to the model of Lin et al., 2012).

\subsection{Global budgets}

Tables 4 and 5 summarize the global budgets of gas phase nitric acid and aerosol nitrate as well as gas phase ammonia and aerosol ammonium for the PD and PI scenarios calculated by the hybrid dynamic method on the five externally mixed pre-existing aerosol types. Here we chose a characteristic height of $5 \mathrm{~km}$ following Textor et al. (2006) and discuss the mass fraction above this height as an indicator of vertical transport. Stronger vertical transport corresponds to slower wet removal rate coefficients in the models (Textor et al., 2006). We also calculate the mass fraction in polar regions which serves as an indicator of horizontal transport. In general, long-range transport is most significant for small particles, which have longer lifetimes.

The total chemical production of gas phase $\mathrm{HNO}_{3}$ is $42.3 \mathrm{Tg} \mathrm{N}$ per year with $24.4 \mathrm{Tg} \mathrm{N}$ per year from reaction of $\mathrm{NO}_{2}$ with $\mathrm{OH}$ and $17.9 \mathrm{Tg} \mathrm{N}$ per year through the heterogeneous conversion of $\mathrm{N}_{2} \mathrm{O}_{5}$ on aerosols, respectively. $38 \%$ of the gaseous $\mathrm{HNO}_{3}$ removal is due to the formation of particulate nitrate including $8.8 \mathrm{Tg} \mathrm{N}$ per year in the fine-mode and $7.2 \mathrm{Tg} \mathrm{N}$ per year in the coarse-mode while $10 \%$ of the gas-phase $\mathrm{HNO}_{3}$ loss (i.e. $4.3 \mathrm{Tg} \mathrm{N}$ per year) is through the photolysis of $\mathrm{HNO}_{3}$ and its reaction with $\mathrm{OH}$. The gaseous $\mathrm{HNO}_{3}$ burden in the troposphere (i.e. for the model layers below $200 \mathrm{hPa}$ ) is calculated to be $0.3 \mathrm{Tg} \mathrm{N}$ with a lifetime of 4.8 days. In contrast, the estimated lifetime of aerosol nitrate is about 4 days. The average rate coefficient for wet removal of nitric acid is about 0.21 per day and this process contributes $65 \%$ of the total removal. As shown in Table 4 , about $81 \%$ of the nitric acid burden is above $5 \mathrm{~km}$. The mass fraction of gaseous nitric acid at the poles is $2 \%$, close to that predicted for sulfate aerosol as reported in Wang et al. (2009). Our predicted total nitrate burden, $0.17 \mathrm{Tg} \mathrm{N}$, is close to the $0.19 \mathrm{Tg} \mathrm{N}$ predicted using the internal mixture approach in FP07. However, in this model $23 \%$ of the nitrate mass is associated with pure sulfate with the remaining nitrate mass associated with sulfate-coated aerosols ( $2 \%$ on 

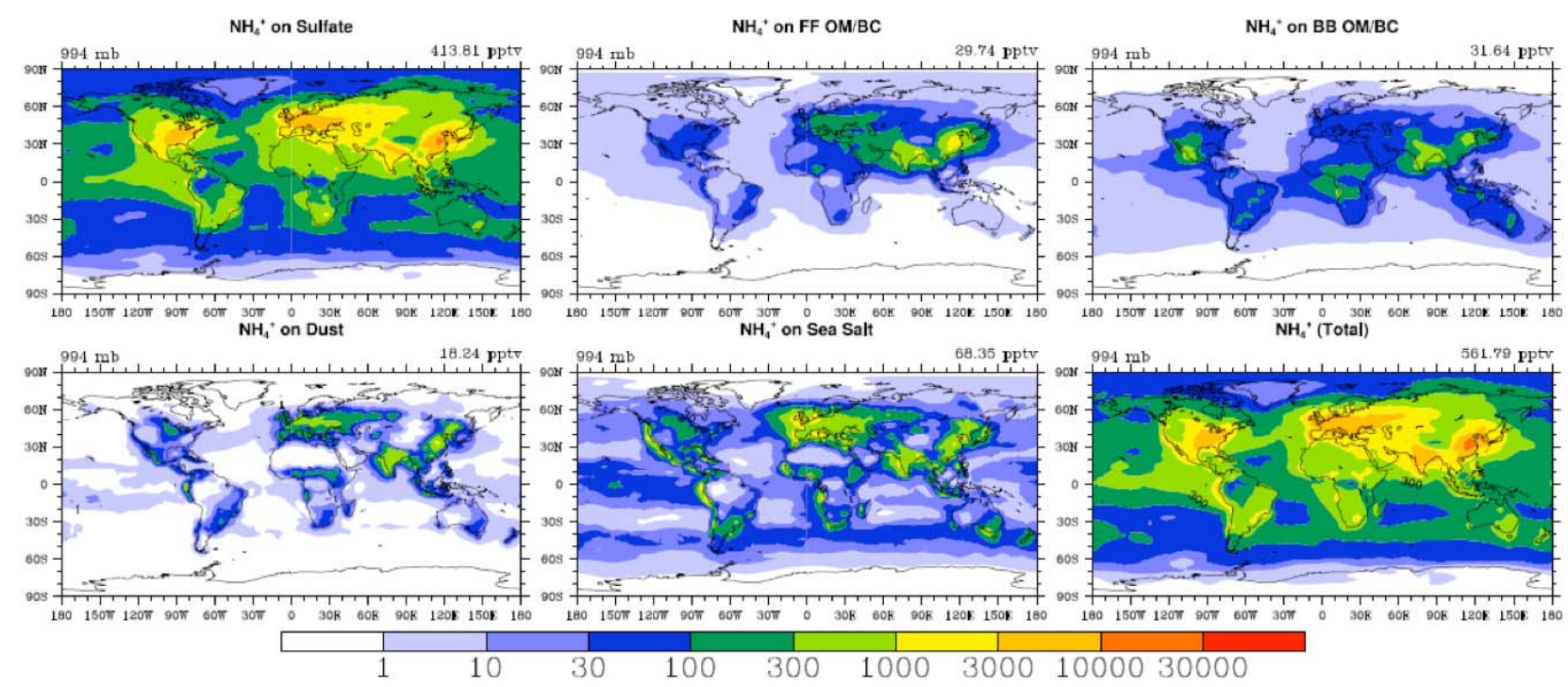

Fig. 5. Predicted annual average mixing ratios (pptv) of ammonium associated with each aerosol type and for the total ammonium aerosols (bottom right) in the surface layer. The pressure level of the surface layer together with the average mixing ratio for that layer is indicated at each panel.

carbonaceous aerosols, $58 \%$ on dust and $17 \%$ on sea salt). About $24 \%$ of nitrate mass is above $5 \mathrm{~km}$ while $1 \%$ of nitrate mass are predicted at poles. The total removal rate calculated in this work is 0.25 per day with $75 \%$ through wet deposition. For the PI scenario, the total burden of nitric acid and aerosol nitrate is $0.15 \mathrm{Tg} \mathrm{N}$ and $0.08 \mathrm{Tg} \mathrm{N}$, respectively, which are nearly half as large as the values for the PD scenario.

Table 5 presents the global and annual average budgets for gas-phase ammonia and particulate ammonium in the troposphere (i.e. for the model layers below $200 \mathrm{hPa}$ ). Nearly half of the total ammonia emissions (i.e. 53.6 $\mathrm{Tg} \mathrm{N}$ per year) are partitioned into the aerosol phase. As a result, the deposition of gas phase ammonia is close to that of particulate ammonium. However, $57 \%$ of the gas-phase ammonia is removed from the atmosphere through dry deposition while $85 \%$ of ammonium is removed by wet deposition. This is similar to the percentages reported in FP07 and A99. The lifetime of ammonium aerosols, 3.2 days, is much longer than that of gas phase ammonia, 0.46 day. As a result, there is nearly four times as much particulate ammonium, $0.26 \mathrm{Tg} \mathrm{N}$, as gas phase ammonia, $0.07 \mathrm{Tg} \mathrm{N}$, on an annual average basis. The mass fraction of gaseous ammonia at the poles is negligible. The model predicts $79 \%$ of the total ammonium mass is associated with pure sulfate with the remaining ammonium coated on non-sulfate aerosols (17\% on carbonaceous aerosols, $1 \%$ on dust and $3 \%$ on sea salt). The mass fraction of ammonium predicted in fine-mode aerosols is $97 \%$ because of the close tie between ammonium aerosol and sulfate. About $13 \%$ of the total ammonium mass is above $5 \mathrm{~km}$. The total burden of ammonia and ammonium for the PI sce- nario is $0.01 \mathrm{Tg} \mathrm{N}$ and $0.03 \mathrm{Tg} \mathrm{N}$, which is equivalent to a reduction by a factor of seven and eight, respectively, from the PD scenario.

The current model predicts a burden of nitrate and ammonium that is $10 \%$ and $4 \%$ lower, than those in FP07, respectively. Our study has higher total sources and sinks, and, therefore, shorter lifetimes by $25 \%$ and $18 \%$ for aerosol nitrate and ammonium (Xu, 2012). These differences are caused by the different treatments for the interaction between nitric acid and ammonia and pre-existing aerosols as well as by different deposition schemes (since our scheme assumes external mixtures and FP07 do not).

\section{Aerosol optical properties}

Here, we use an off-line radiative transfer model to compute the aerosol optical properties and the resulting radiative forcing (Chen and Penner, 2005; Wang and Penner, 2009). As in the global transport model, we assume that the five types of aerosol populations (i.e. pure sulfate, carbonaceous aerosols from fossil fuel, carbonaceous aerosols from biomass burning, dust and sea salt) are externally mixed, but that all aerosol components are internally mixed within each aerosol type. The refractive indices of sulfate (1.53$10^{-7} \mathrm{i}$ at $\left.550 \mathrm{~nm}\right)$, dust $(1.53-0.0014 \mathrm{i}$ at $550 \mathrm{~nm})$ and sea salt $\left(1.38-5.8 \times 10^{-7} \mathrm{i}\right.$ at $\left.550 \mathrm{~nm}\right)$ and their densities are the same as those used in Liu et al. (2007). The refractive index and density of fossil fuel BC (1.85-0.71i at $550 \mathrm{~nm}$ and $1800 \mathrm{~kg} \mathrm{~m}^{-3}$ ) are taken from Bond et al. (2006) while those of biomass burning $\mathrm{BC}(1.75-0.46 \mathrm{i}$ at $550 \mathrm{~nm}$ and $1000 \mathrm{~kg} \mathrm{~m}^{-3}$ ) are those used by Zhang et al. (2005). The 
Table 5. Global Annual budgets of $\mathrm{NH}_{3}(\mathrm{~g})$ and ammonium $\left(\mathrm{NH}_{4}^{+}\right)$for present-day and pre-industrial scenarios.

\begin{tabular}{|c|c|c|}
\hline & \multicolumn{2}{|c|}{ Scenario } \\
\hline & Present-Day & Pre-industrial \\
\hline \multicolumn{3}{|l|}{$\mathrm{NH}_{3}(\mathrm{~g})$} \\
\hline Emission $\left(\mathrm{Tg} \mathrm{N} \mathrm{yr}^{-1}\right)$ & 53.60 & 10.71 \\
\hline $\operatorname{Loss}\left(\operatorname{Tg~N~yr}^{-1}\right)$ & 53.60 & 10.71 \\
\hline Loss to ammonium & 30.52 & 5.87 \\
\hline Dry deposition & 12.71 & 2.33 \\
\hline Wet deposition & 9.63 & 2.36 \\
\hline Burden $(\operatorname{Tg} N)$ & 0.07 & 0.01 \\
\hline Above 5 km (\%) & 0.76 & 0.51 \\
\hline In polar $(\%)$ & 0.003 & 0.05 \\
\hline Lifetime & 0.46 & 0.73 \\
\hline Removal rate $\left(\right.$ day $\left.^{-1}\right)$ & 0.90 & 1.37 \\
\hline Wet & 0.39 & 0.69 \\
\hline Dry & 0.51 & 0.68 \\
\hline Wet $(\%)$ & 43.04 & 50.28 \\
\hline \multicolumn{3}{|l|}{$\mathrm{NH}_{4}^{+}$} \\
\hline Sources $\left(\mathrm{Tg} \mathrm{N} \mathrm{yr}^{-1}\right)$ & 30.52 & 5.87 \\
\hline Gas-to-aerosol $(D<1.25 \mu \mathrm{m})$ & 27.46 & 5.32 \\
\hline Gas-to-aerosol $(D>1.25 \mu \mathrm{m})$ & 3.06 & 0.55 \\
\hline Loss $\left(\operatorname{Tg~N~yr}^{-1}\right)$ & 30.44 & 5.93 \\
\hline Dry deposition & 4.51 & 0.74 \\
\hline Wet deposition & 25.93 & 5.19 \\
\hline Burden $(\operatorname{Tg} N)$ & 0.26 & 0.03 \\
\hline On pure sulfate $(\%)$ & 79.12 & 80.95 \\
\hline On carbonaceous aerosols $(\%)$ & 17.05 & 14.53 \\
\hline On dust bins $1-4(\%)$ & $0.07,0.88,0.18,0.03$ & $0.01,0.14,0.04,0.05$ \\
\hline On sea salt bins $1-4(\%)$ & $1.03,1.00,0.55,0.09$ & $1.09,2.01,1.02,0.17$ \\
\hline Fine-mode $(D<1.25 \mu \mathrm{m})$ & 97.26 & 96.57 \\
\hline Coarse-mode $(D>1.25 \mu \mathrm{m})$ & 2.74 & 3.43 \\
\hline Above 5 km (\%) & 13.00 & 11.32 \\
\hline In polar $(\%)$ & 0.54 & 0.54 \\
\hline Lifetime & 3.23 & 2.19 \\
\hline Removal rate $\left(\right.$ day $\left.^{-1}\right)$ & 0.31 & 0.46 \\
\hline Wet & 0.26 & 0.40 \\
\hline Dry & 0.05 & 0.07 \\
\hline Wet $(\%)$ & 85.14 & 87.48 \\
\hline
\end{tabular}

refractive index of organic matter (OM) in biomass burning was that of Kirchstetter et al. (2004) (1.53-0.03i at $550 \mathrm{~nm}$ ), while $50 \%$ of organic matter originating from fossil fuel combustion also used this refractive index, to account for the fact that some of this material is absorbing. The rest of the organic matter used the same refractive index as that of ammonium sulfate throughout the spectrum. Refractive indices of ammonium sulfate are used for ammonium. Refractive indices of nitrate at the 19 wavelengths used for the radiative forcing calculation are taken from the Global Aerosol Climatology Project database (http://gacp.giss.nasa.gov/data_sets). The refractive indices of each internal mixture are calculated by volume-weighting the refractive indices of each individual aerosol species including its associated water.

The nitrate and ammonium for each aerosol type (Table 3) is output for use in the off-line radiation model, but these components must be distributed within each size bin and type in order to accurately calculate the radiative properties. Therefore, we calculate the size distribution of pure sulfate using the predicted mass and number and the assumed geometric standard deviation (i.e. 1.514 and 1.776, respectively, for the nuclei and accumulation modes) for a log-normal distribution at each grid (Liu et al., 2005) while the other four types of aerosols use the prescribed size distributions given in Table 1. We assumed that two ammonium cations are first 

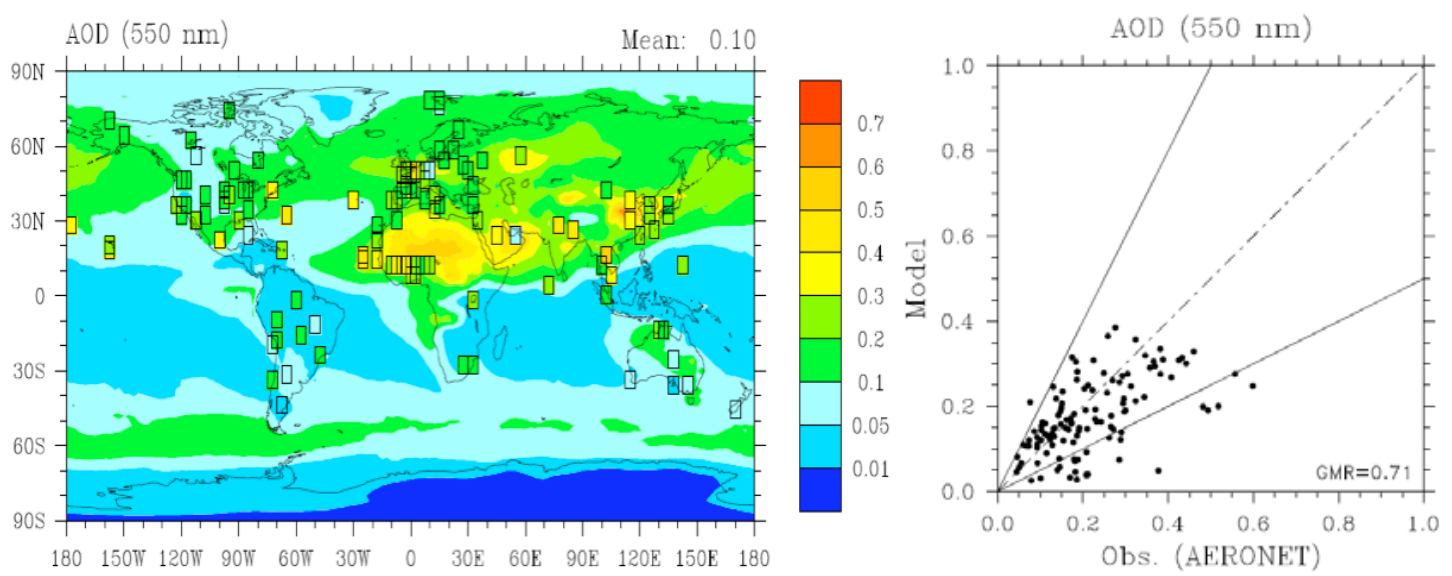

Fig. 6. Global annual mean distribution (left) and scatter plot (right) of modeled aerosol optical depth and observational data from AERONET at $550 \mathrm{~nm}$. Observational data were provided by S. Kinne and included all available level 2 data from 1996 to 2010 . The geometric mean ratio (GMR) between modeled and observed values is given.

associated with one sulfate anion to form ammonium sulfate before they are allowed to be associated with nitrate to form ammonium nitrate. This assumption is valid over most continental areas since the gas ratio is generally higher than 1 (Fig. 4, bottom panel). For pure sulfate, nitrate is allocated to each sulfate size bin in the accumulation mode according to the surface area fraction of that size bin to the total surface area. For the other four aerosol types, sulfate, ammonium and nitrate are distributed into each size bin proportional to the surface area of that type. We use Köhler theory together with the soluble fraction present on each type of aerosols to predict the amount of water on each aerosol type. The hygroscopicity or Kappa value of nitrate is assumed to be 0.67 (Petters and Kreidenweis, 2007), higher than that for ammonium sulfate, 0.51 . The hygroscopicity of the other aerosols is $1.16,0.14,0.14$, and $5 \times 10^{-7}$ for sea salt, organic matter, dust and black carbon, respectively (see Ghan et al., 2001). The organic value we use here, 0.14 , is somewhat higher than the average Kappa value reported in Jimenez et al. (2009) but seems reasonable for the more oxidized compounds that represent the organics in aerosols at longer time scales (Lin et al., 2012). Note that sea salt is the most hygroscopic of all the aerosols. The hygroscopicity of the internal mixture within each aerosol type is calculated by volume-weighting the hygroscopicity of each of the individual aerosol species. Aerosol optical depth (AOD) was calculated using a three dimensional lookup table that included the optical properties from a Mie scattering calculation, whose independent variables were the real and imaginary refractive indices and the size parameter $(x=2 \pi r / \lambda$, where $r$ and $\lambda$ are the aerosol radius and wavelength, respectively), so that arbitrary internal mixtures and sizes of aerosols could be included. In the present study, we used monthly averaged aerosol concentrations in the radiative transfer model. Sensitivity tests using daily and hourly aerosol concentrations were examined in $\mathrm{Xu}$
(2012) and the results were within 5\% for the direct effect and $10 \%$ for the indirect effect. The relative humidity data used the 4-hourly meteorology field that was used to drive the off-line radiation transfer model described in Wang and Penner (2009).

Predicted annual average aerosol optical depth is compared with the annual averaged observational data derived from the AERONET provided by S. Kinne (Max Planck Institute for Meteorology) in Fig. 6. The modeled highest AODs are found over Europe, eastern Asia and over the Sahara desert and range from 0.4 to 0.6. The highest AODs in Eastern North America are around 0.1 to 0.3. In general, the modeled AOD is within a factor of 2 of the observed data from the AERONET. However, the geometric mean ratio between modeled and observed AOD is 0.71 indicating that the model underestimates AOD. The modeled AOD over the ocean can be lower than that observed if sea salt emissions are too low. Over continents, the modeled AOD captures the general spatial pattern of AOD although the magnitude is smaller than the observations, especially over South America. Low values in these regions may be due to low biomass burning emissions. Modeled optical depths in the Arabian Sea (0.1-0.4) and Indian Ocean (0.1-0.2) are within the range of values observed during the Indian Ocean Experiment (INDOEX) by Jayaraman et al. (1998) (i.e. 0.2-0.4 and about 0.1 , respectively).

Figure 7 shows a comparison between the modeled annual mean global distribution of single scattering albedo (SSA) at $550 \mathrm{~nm}$ and observation sites from the AERONET. The modeled SSA over the North America generally ranges from 0.75 to 0.96 . The simulated SSA ranges from 0.9 to 0.96 over Eastern Europe and 0.85-0.9 in Western Europe. The SSA over regions with biomass burning aerosols and mineral dust are generally lower than 0.9 and 0.93 , respectively. The modeled SSA generally agrees with the observations from 

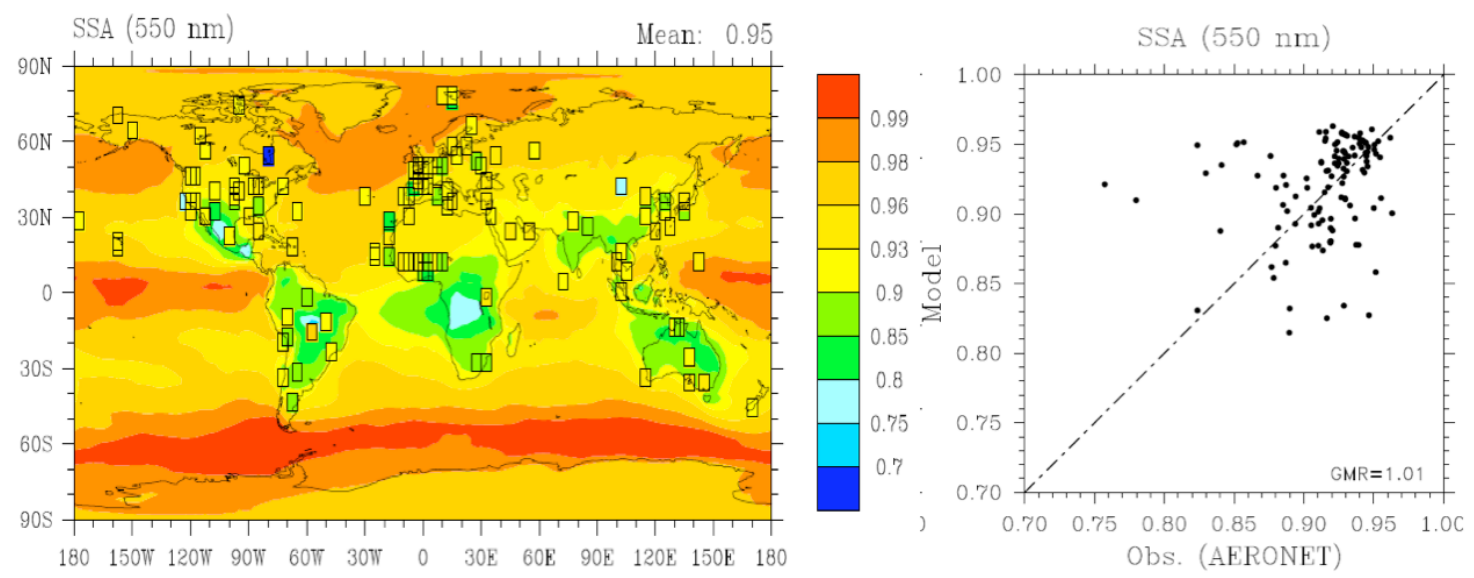

Fig. 7. Global annual mean distribution (left) and scatter plot (right) of modeled aerosol single scattering albedo and observational data from AERONET at $550 \mathrm{~nm}$. The geometric mean ratio (GMR) beteween modeled and observed values is given.
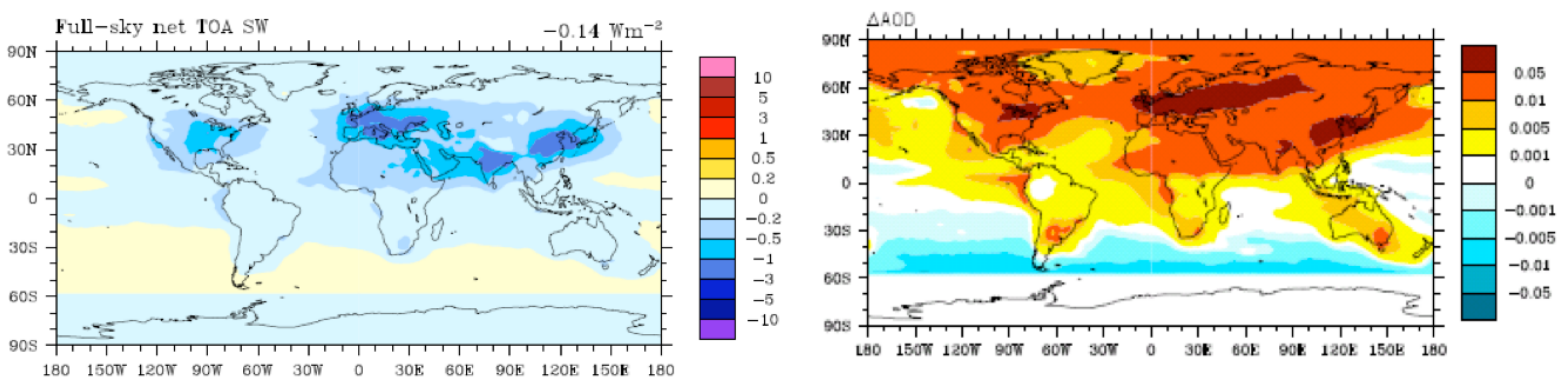

Fig. 8. Annual mean distribution of the simulated radiative effects of nitrate and ammonium at the top of atmosphere (TOA) for the all-sky condition for the PD simulation (left) and global annual mean distribution of the difference in aerosol optical depth at $550 \mathrm{~nm}(\Delta \mathrm{AOD})$ between the simulations with and without ammonium and nitrate aerosols for the PD scenario (right).

AERONET with a geometric mean ratio between modeled and observed values of 1.01 although we slightly underestimate the SSA over biomass burning regions (e.g. South America).

\section{Radiative forcing of nitrate and ammonium}

The direct and indirect radiative effects of nitrate and ammonium aerosols were calculated for both present-day and preindustrial emissions. Note that the same meteorology field (i.e. cloud fields, relative humidity) is used for both PI and PD simulations. The radiative effect, here, is defined as the difference in the net incoming radiative flux with and without both nitrate and ammonium aerosols for both the PD and the PI scenarios. As in IPCC, the total direct or indirect anthropogenic forcing by nitrate and ammonium aerosols is defined as the difference in the net radiative flux between the PD and PI scenarios due to the change in anthropogenic emissions of nitrate and ammonium precursors. The global annual mean forcing is assessed based on the average of the four-month simulated results (i.e. January, April, July and October).

\subsection{Direct forcing of nitrate and ammonium}

Figure 8 (left panel) shows the annual mean distribution of the simulated direct radiative effect of nitrate and ammonium at the top of atmosphere (TOA) for all-sky conditions for the PD simulation. The inclusion of nitrate and ammonium contributes to cooling of up to $-3 \mathrm{~W} \mathrm{~m}^{-2}$ over continents but a slight warming $\left(0.2 \mathrm{~W} \mathrm{~m}^{-2}\right)$ over the oceans in regions with high sea salt concentrations. The warming effect over ocean is expected since nitrate and ammonium lowers the ability of sea salt aerosols to take up water, which then decreases the extinction characteristics of sea salt aerosols shown in Fig. 8 (right panel). Figure 8 (right panel) shows global annual mean distribution of the difference in aerosol optical depth at $550 \mathrm{~nm}$ between the simulations with and without ammonium and nitrate aerosols for the PD simulation. A decrease in the aerosol optical depth at $550 \mathrm{~nm}$ including nitrate 
Table 6. Comparison of direct radiative effect and anthropogenic forcing $\left(\mathrm{W} \mathrm{m}^{-2}\right)$ of nitrate and ammonium in this work with other studies.

\begin{tabular}{lcc|cc|cc|c}
\hline & \multicolumn{2}{c|}{ Direct effect (PD) } & \multicolumn{2}{|c|}{ Direct effect (PI) } & \multicolumn{2}{|c|}{ Anthropogenic forcing } & Total direct effect ${ }^{\mathrm{g}}$ \\
\cline { 2 - 7 } & TOA & Surface & TOA & Surface & TOA & Surface & \\
\hline This work & -0.14 & -0.18 & -0.02 & -0.02 & -0.12 & -0.16 & $-0.3(-0.1 \sim-0.9)$ \\
M09 $^{\mathrm{a}}$ & & & & & -0.023 & & \\
B07 $^{\mathrm{b}}$ & -0.11 & & -0.05 & & -0.06 & & \\
L04 $^{\mathrm{c}}$ & -0.14 & -0.17 & & & & \\
L05 $^{\mathrm{d}}$ & -0.22 & -0.21 & -0.06 & -0.06 & -0.16 & -0.15 & \\
J01 $^{\mathrm{e}}$ & -0.07 & -0.07 & & & & & \\
A01 & -0.30 & & -0.11 & & -0.19 & & \\
\hline
\end{tabular}

${ }^{\mathrm{a}}$ Myhre et al. (2009); ${ }^{\mathrm{b}}$ Bauer et al. (2007); ${ }^{\mathrm{c}}$ Liao et al. (2004); ${ }^{\mathrm{d}}$ Liao and Seinfeld (2005); ${ }^{\mathrm{e}}$ Jacobson et al. (2001); ${ }^{\mathrm{f}}$ Adams et al. (2001); $\mathrm{g}$ the value outside and inside of the parentheses represent the total direct whole sky forcing from all aerosol components and the total aerosol direct effect summarized in AR4, respectively.

and ammonium is found over the Southern Oceans and part of North Pacific Ocean.

Table 6 shows a comparison of direct effect and anthropogenic forcing of nitrate and ammonium estimated in this work with other studies. The direct effect of nitrate and ammonium at TOA for the present-day in this work is estimated to be $-0.14 \mathrm{~W} \mathrm{~m}^{-2}$. Other models have estimated significantly lower forcing $\left(-0.07 \mathrm{~W} \mathrm{~m}^{-2}\right.$ estimated by Jacobson et al., 2001) and higher forcing $\left(-0.30 \mathrm{~W} \mathrm{~m}^{-2}\right.$ by Adams et al., 2001). As noted by FP07, the equilibrium treatment of Jacobson et al. (2001) would be expected to have far too much nitrate in larger aerosols, while that by Adams et al. (2001) might have higher forcing, because the formation of nitrate and ammonium on dust and sea salt particles was neglected entirely. The direct effect of nitrate and ammonium at the surface estimated in this work, $-0.18 \mathrm{~W} \mathrm{~m}^{-2}$, is comparable to that by Liao et al. (2004).

Figure 9 shows annual average direct anthropogenic forcing of nitrate and ammonium at TOA for all-sky conditions. The nitrate and ammonium forcing is estimated to be $-0.12 \mathrm{~W} \mathrm{~m}^{-2}$, much larger than the value of $-0.023 \mathrm{~W} \mathrm{~m}^{-2}$ in M09 and somewhat smaller than the $-0.19 \mathrm{~W} \mathrm{~m}^{-2}$ in A01. Again, A01 neglected the effects of dust and sea salt, but it is not clear why the results in M09 are so much smaller. There is a cooling of up to $-3 \mathrm{~W} \mathrm{~m}^{-2}$ over Eastern Asia, North America and Europe, which is consistent with the areas where nitrate and ammonium aerosols are highest. The anthropogenic nitrate and ammonium direct forcing at the surface given in Table 6 is $-0.16 \mathrm{~W} \mathrm{~m}^{-2}$, which is comparable to the $-0.15 \mathrm{~W} \mathrm{~m}^{-2}$ estimated by Liao et al. (2005). Note that this work predicts a smaller nitrate burden for both PD and PI simulation compared with the values reported in Liao et al. (2005) but the change of the nitrate burden from the PI scenario to the PD scenario (i.e. roughly an increase of a factor of 2) is close between these two studies, which results in a similar anthropogenic forcing of nitrate and ammonium. Figure 10 shows the annual average total direct anthropogenic forcing of all aerosol components at

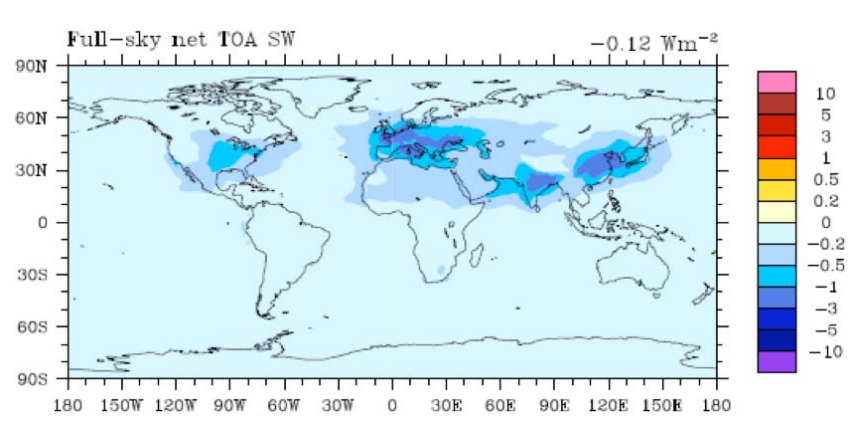

Fig. 9. Annual mean direct anthropogenic forcing of nitrate and ammonium from the PI to PD scenario for all-sky conditions.

the TOA for all-sky conditions (left panel) and for clearsky conditions (right panel). At the top of atmosphere, the total global annual anthropogenic forcing for all-sky conditions is estimated to be $-0.3 \mathrm{~W} \mathrm{~m}^{-2}$, which is within the range of $-0.1 \sim-0.9 \mathrm{~W} \mathrm{~m}^{-2}$ reported by AR4 (Forster et al., 2007) and, somewhat by accident, close to the suggested global annual mean radiative forcing of $-0.3 \mathrm{~W} \mathrm{~m}^{-2}$ by Myhre (2009) (since our nitrate/ammonium forcing is so different). The all-sky direct forcing shows a strong cooling over industrial regions with moderate heating occurring over biomass burning regions. The total cooling by anthropogenic aerosols would be significantly larger, but it is masked by the shortwave cloud forcing (i.e. the clear sky forcing is $-0.91 \mathrm{~W} \mathrm{~m}^{-2}$ at the top of atmosphere while the all-sky forcing is $-0.3 \mathrm{~W} \mathrm{~m}^{-2}$ ). For clear-sky conditions, aerosols generally exert negative forcing at TOA with a strong cooling of up to $-10 \mathrm{~W} \mathrm{~m}^{-2}$ over East Asia, Europe and North America in which anthropogenic aerosols are highest. Note that the inclusion of absorbing aerosols (BC and/or OM) in biomass burning regions can cause heating when the aerosol is above a cloud or above a reflecting surface (Haywood and Shine, 1995). In clear skies, aerosols would only heat if the surface albedo is large and the proportion of absorbing material is large enough. Although we use a refractive index for $\mathrm{OM}$ in 

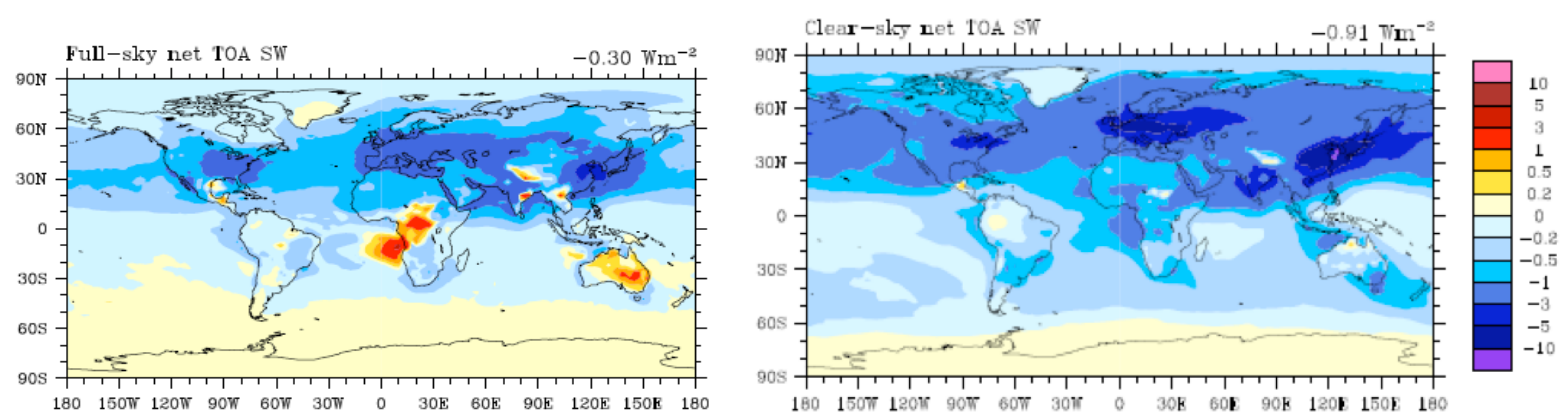

Fig. 10. Annual mean total direct anthropogenic forcing of all aerosols at the top of atmosphere from the PI to PD scenario for all-sky conditions (left) and for clear-sky conditions (right).

biomass aerosols that represents the absorption seen in measurements (Kirchstetter et al., 2004), we do not find that this absorption leads to a positive forcing in clear skies (whereas Chuang et al. (2012) do find a positive forcing). The contribution of aerosol nitrate and ammonium to the global average total clear sky direct anthropogenic forcing is approximately $13 \%$.

\subsection{Indirect forcing of nitrate and ammonium}

Here, we investigate the aerosol indirect effect of nitrate and ammonium and its accompanying gaseous $\mathrm{HNO}_{3}$ in the atmosphere. The treatment for gas phase $\mathrm{HNO}_{3}$ is based on the substitution method proposed in a previous study (Chen, 2006). Chen (2006) used a cloud parcel model to investigate the use of different assumptions for the treatment of nitrate in the gas phase and aerosol phase to calculate the cloud droplet number concentrations for different representative sites on the Earth. In keeping with the results of Kulmala et al. (1993), he found that both nitrate in the aerosol phase and $\mathrm{HNO}_{3}$ in gas phase can have an effect on aerosol activation. Kulmala et al. (1993) showed that in the presence of $\mathrm{HNO}_{3}$ gas, the supersaturation needed to activate aerosol particles is suppressed. As a result, smaller particles can be activated more easily at high concentrations of $\mathrm{HNO}_{3}$. Since the droplet number is mainly determined by the fine-mode aerosol number, Chen (2006) proposed to re-distribute the gas-phase $\mathrm{HNO}_{3}$ to the fine-mode aerosol phase and to use this together with the Abdul-Razzak and Ghan (2002) parameterization scheme to approximate the effect of gaseous $\mathrm{HNO}_{3}$ on cloud droplet number concentrations in global models. Chen (2006) used an adiabatic parcel model and showed that the substitution method used in a parcel model captures the increase of cloud droplets due to the condensation of nitric acid gas to within a root-mean-square (RMS) of 5\%. The Abdul-Razzak and Ghan (2002) scheme, however, has additional approximations that cause additional errors (RMS difference of $20 \%$ ) between the parcel model and their parameterization with the substitution method. In this work, we implemented this treatment in the off-line calculation of forcing developed by Wang and Penner (2009). Thus, we account for the influence of both gaseous $\mathrm{HNO}_{3}$ and aerosol nitrate and ammonium on the estimated cloud droplet number concentrations. In order to calculate these effects, first, we calculated the cloud droplet number from the five individual aerosol types $\left(N_{\mathrm{d}, j}\right.$, where $j$ is aerosol type) and the total cloud droplet number (i.e. $N_{\mathrm{d}}=\sum_{j=1}^{5} N_{\mathrm{d}, j}$ ) without considering the effect of nitric acid gas. Thus, we only consider the influence of particulate phase nitrate and ammonium on cloud droplet activation in this step. Then, we distribute the mass of nitric acid gas to each aerosol type in the fine mode (i.e. size bin 1) proportional to the fraction of cloud droplets formed on this aerosol type (i.e. $f_{j}=N_{\mathrm{d}, j} / N_{\mathrm{d}}$ ). Last, we updated the cloud droplet number with this new nitrate aerosol distribution.

Generally speaking, $\mathrm{HNO}_{3}$ gas and aerosol nitrate/ammonium have two counteracting effects in modifying cloud droplet number concentrations. First, the addition of total nitrate (gas plus aerosol) and ammonium increases the size and the solute concentration in the aerosol particles, which increases the hygroscopicity and leads to a decrease in the critical supersaturation $\left(S_{\mathrm{c}}\right)$ due to Raoult effect (or "solute effect"). This solute effect is closely tied with the soluble fraction in pre-existing aerosols. If the pre-existing aerosol is soluble, the effect of aerosol-phase ammonium and nitrate and gas-phase nitric acid may not be of great importance. If the pre-existing aerosol is mainly non-soluble, the addition of soluble aerosol and gas species can increase the uptake of water, thereby causing an increase in the number of cloud droplets. Second, the effect of total nitrate on cloud droplets is also related to the total mass of nitrate and $\mathrm{HNO}_{3}$ gas. An increase in the total mass of the aerosol particle population due to the presence of nitrate and ammonium aerosols and $\mathrm{HNO}_{3}$ gas tends to decrease the ambient maximum supersaturation $\left(S_{\max }\right)$. In this case, nitrate lowers the saturation water vapor associated with aerosol particles, leading to a decrease in the size of particles that activate at a given supersaturation. Based on the theory 
Table 7. Descriptions of experiments for the radiative calculations of the first aerosol indirect forcing.

\begin{tabular}{ll}
\hline Case & Description \\
\hline $\mathrm{PN}$ & $\begin{array}{l}\text { The calculation with all aerosols including particulate } \\
\mathrm{NO}_{3}^{-} \text {and } \mathrm{NH}_{4}^{+}\end{array}$ \\
\hline $\mathrm{TN}$ & $\begin{array}{l}\text { The calculation including particulate } \mathrm{NO}_{3}^{-} \text {and } \\
\mathrm{NH}_{4}^{+} \text {and gaseous } \mathrm{HNO}_{3} .\end{array}$ \\
\hline $\mathrm{NN}$ & $\begin{array}{l}\text { The calculation without } \mathrm{NO}_{3}^{-} \text {and } \mathrm{NH}_{4}^{+} \text {but including } \\
\text { sulfate, carbonaceous aerosols from both fossil fuel and } \\
\text { biomass burning, dust and sea salt. }\end{array}$ \\
\hline
\end{tabular}

of activation, aerosol particles with $S_{\mathrm{c}}<S_{\max }$ are activated to become cloud droplets and will grow spontaneously if the ambient supersaturation remains at or above the respective critical value. Hence, the number of droplets depends on the competition between the increasing effect of the lower critical supersaturations and the decreasing effect of the lower ambient maximum supersaturations within the parcel. In addition, the number of cloud droplets that form is related to how the soluble gases are distributed among the particles with different sizes. If small particles collect comparably more gases than larger particles, this favors the increasing aerosol activation while the number of cloud drops may decrease if larger particles take up gases more easily.

Table 7 outlines the experiment designs for the radiative calculations of the first aerosol indirect forcing. We ran two radiative calculations for the three cases listed in Table 7: one with the PD aerosol concentrations and one with the PI aerosol concentrations. The difference in the radiative flux between the total nitrate case (TN) and particulate nitrate (PN) cases (i.e. TN-PN) is the net effect of $\mathrm{HNO}_{3}$ gas while the difference between TN and $\mathrm{NN}$ (no nitrate) is the total nitrate $\left(\mathrm{NO}_{3}^{-}+\mathrm{HNO}_{3}\right.$ gas) and ammonium effect.

Figure 11 shows the present day annual average cloud top droplet number $(\mathrm{CDN})$ concentration for the three cases. As expected, the influence of nitrate and ammonium aerosols on the cloud droplet activation mainly occurs over the Northern Hemisphere since the major aerosol nitrate and ammonium occurs in the Northern Hemisphere. Because nitrate and ammonium decrease rapidly with altitude (not shown), the largest effects of adding these aerosols are seen close to the surface. There is some modification of cloud droplets between $0-30^{\circ} \mathrm{S}$ in the Southern Hemisphere with the addition of nitric acid gas (i.e. the $\mathrm{TN}$ case) due to higher gas phase $\mathrm{HNO}_{3}$ mixing ratios over these areas. The addition of nitrate and ammonium aerosols increases the cloud droplet number concentration by about $3 \%$ on a global average basis. With the further addition of nitric acid gas, the increase in cloud droplets is more than $10 \%$. Local enhancements are even larger. The spatial pattern of the modeled CDN concentration in this study is similar to that predicted in other

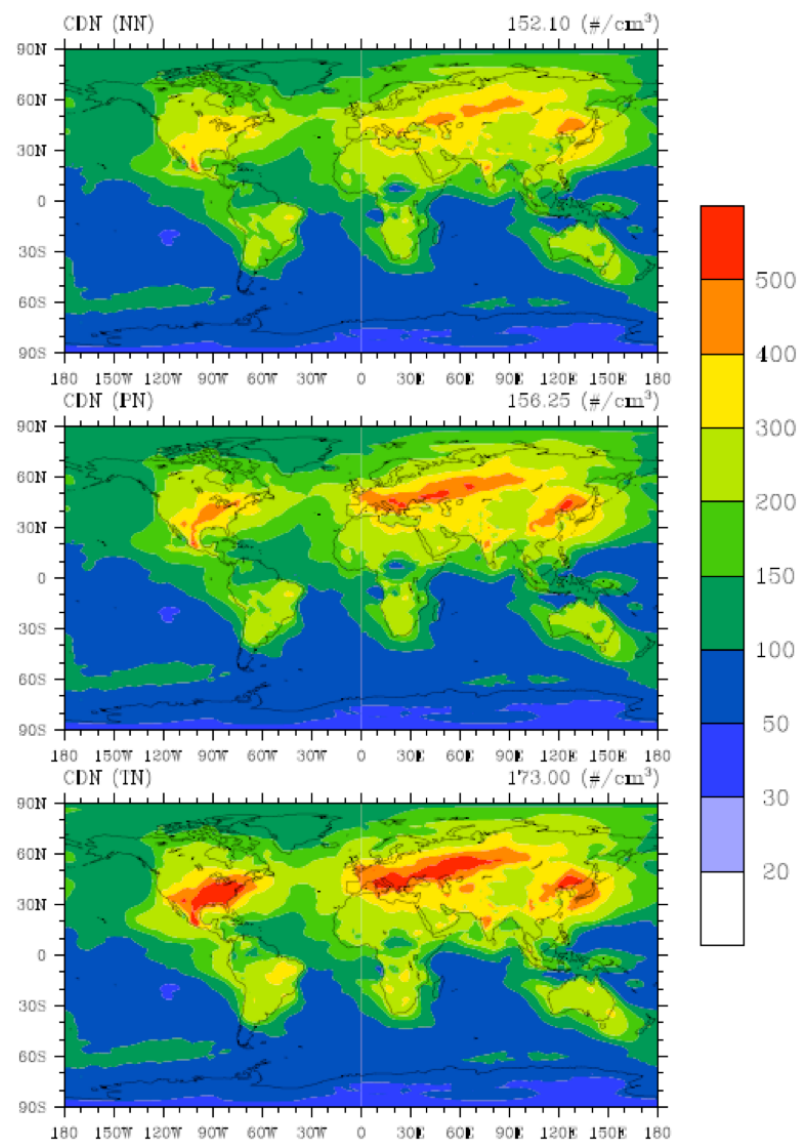

Fig. 11. Present day annual average cloud top droplet number $(\mathrm{CDN})$ concentration for the NN, PN, and TN cases near $930 \mathrm{mb}$ (the third model layer).

global studies (e.g. Merikanto et al., 2010; Karydis et al., 2011). However, the CDN are slightly lower over the polluted regions (less than $500 \mathrm{~cm}^{-3}$ ) than those in Merikanto et al. (2010) and Karydis et al. (2011). Differences in predicted CDN can arise if the assumed in-cloud updraft velocities differ. This study used the updraft velocities chosen in Wang and Penner (2010) which are less than $0.3 \mathrm{~m} \mathrm{~s}^{-1}$ over the land whereas Merikanto et al. (2010) and Karydis et al. (2011) used values of $0.4 \mathrm{~m} \mathrm{~s}^{-1}$ and $0.3 \mathrm{~m} \mathrm{~s}^{-1}$, respectively. Figure 12 shows the absolute difference of present day annual average cloud droplet number near $930 \mathrm{mb}$ (the third model level, near the top of the boundary layer) between the PN and NN cases for each aerosol type. The addition of aerosol nitrate and ammonium increases the number of total cloud droplets almost everywhere except for some areas over oceans. The activated pure sulfate is inhibited with additional nitrate and ammonium except for sulfate concentration peak regions. The reduction of activated pure sulfate results from the increase in the activation of carbonaceous aerosols and dust due to the significant enhancement of their capability to uptake water by more soluble coatings of nitrate and 

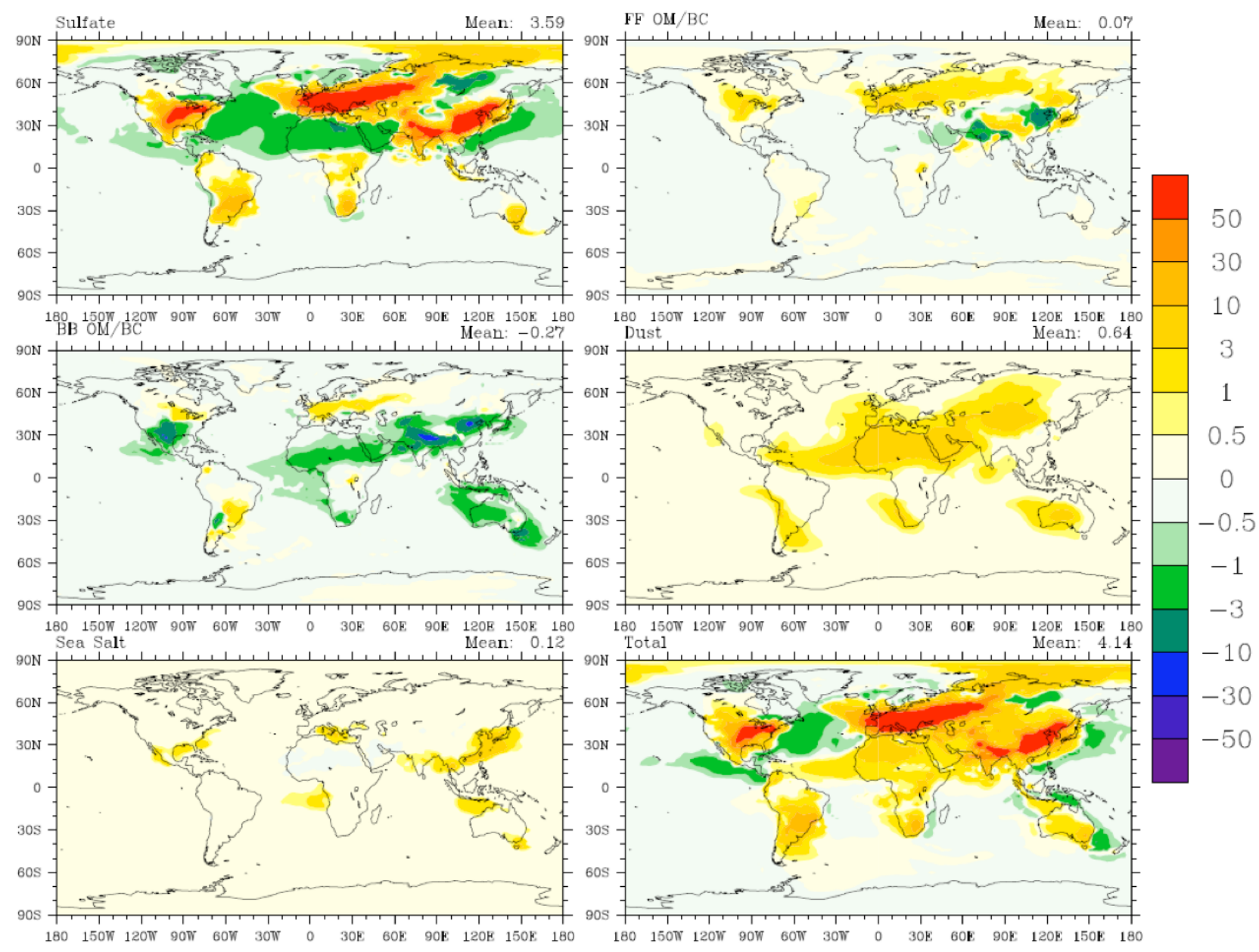

Fig. 12. The absolute difference of present day annual average cloud droplet number concentration activated from each aerosol type and the total cloud droplet number near $930 \mathrm{mb}$ (the third model layer) between the case PN and NN. The mean value is given above each panel.

ammonium besides sulfate. Ghan et al. (1998) showed that the competition between sulfate and sea salt can decrease the influence of sulfate on cloud droplet number concentrations for typical marine cloud conditions. They found that the additional sea salt increases the total number of activated cloud drops for low sulfate concentrations while the number of activated droplets decreases significantly with the additional sea salt for high sulfate concentrations. They explained that the presence of large cloud condensation nuclei $(\mathrm{CCN})$ with larger surface area will enhance condensation, reduce the maximum supersaturation and hence prevent the activation of enough of smaller CCN, eventually resulting in the decrease of the total number of activated drops. This example demonstrates the non-linear dynamical effects that exist in a simple two-component aerosol system (i.e. the effect of increasing the availability of aerosol populations does not necessarily causes an increase in cloud droplet concentration). Here, the decrease in drop numbers formed on sulfate is due to the competition for water vapor in the multi-component system. Figure 13 shows a similar figure for the difference between the $\mathrm{TN}$ case and the $\mathrm{NN}$ case. The additional $\mathrm{HNO}_{3}$ gas in the TN case further enhances the activation of sulfate and carbonaceous aerosols but it does not change the activation of dust and sea salt by a significant amount. This is probably because $\mathrm{HNO}_{3}$ gas is small in regions with abundant dust and sea salt so that the additional $\mathrm{HNO}_{3}$ gas effect is not pronounced on these two types of aerosols. We also see some areas over remote oceans with decreases in cloud drops when $\mathrm{HNO}_{3}$ gas and nitrate and ammonium particles are added, which again might be due to the competition between different aerosol types discussed above (and in Ghan et al., 1998). The negative response of sulfate in Northern America is also due to the dynamic competition for water vapor in the complex multi-component system, which is partly a result of the positive response of fossil fuel and biomass burning aerosols to the additional $\mathrm{HNO}_{3}$ gas (compare Figs. 12 and 13). Overall, the addition of nitrate aerosols increases the number of cloud droplets in eastern Asia while the further addition of nitric acid increases the cloud droplets even more over eastern Asia, Europe, eastern United Sates, South America and 


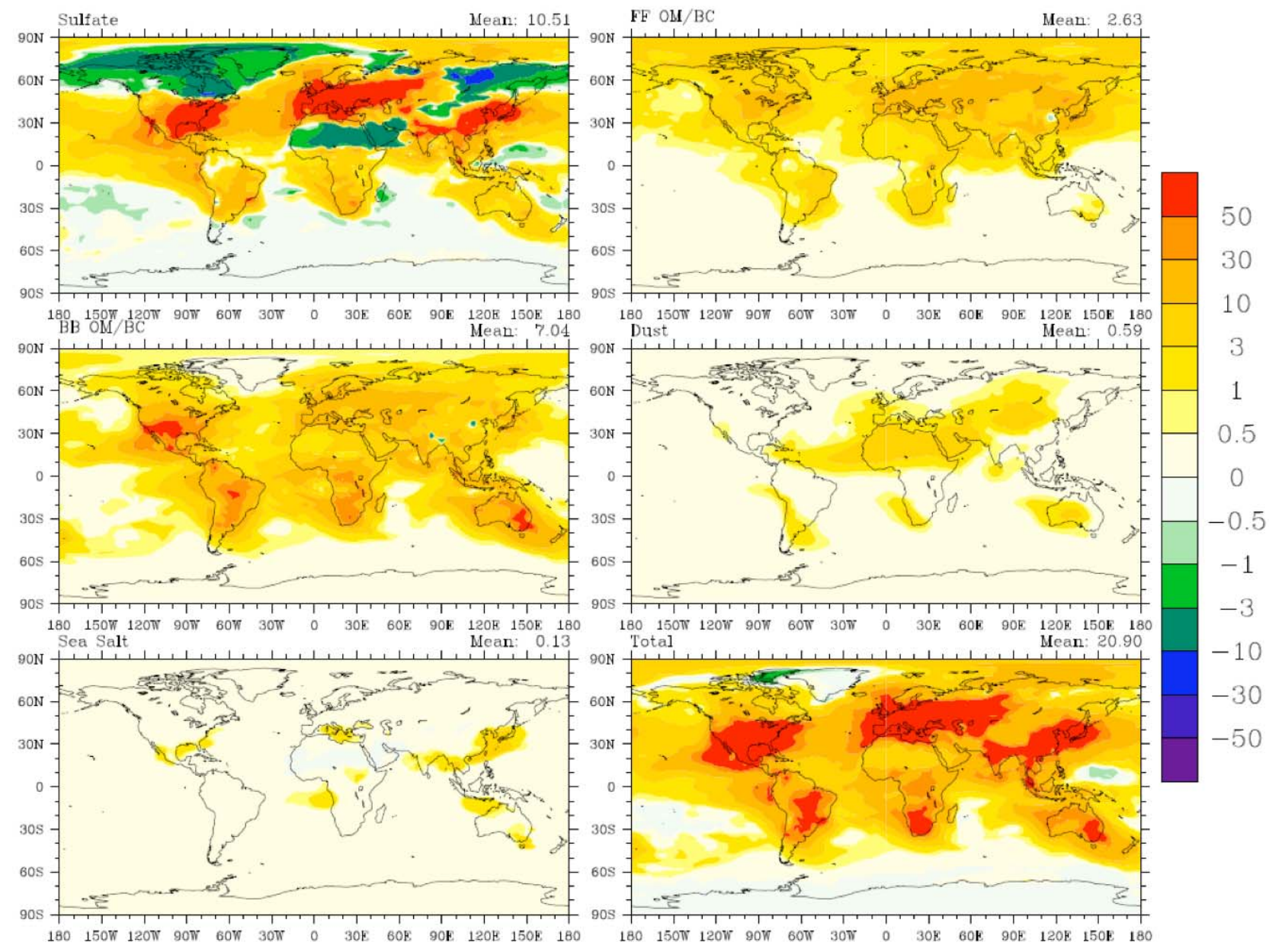

Fig. 13. The absolute difference of present day annual average cloud droplet number concentration activated from each aerosol type and the total cloud droplet number near $930 \mathrm{mb}$ (the third model layer) between the case TN and NN. The mean value is given above each panel.

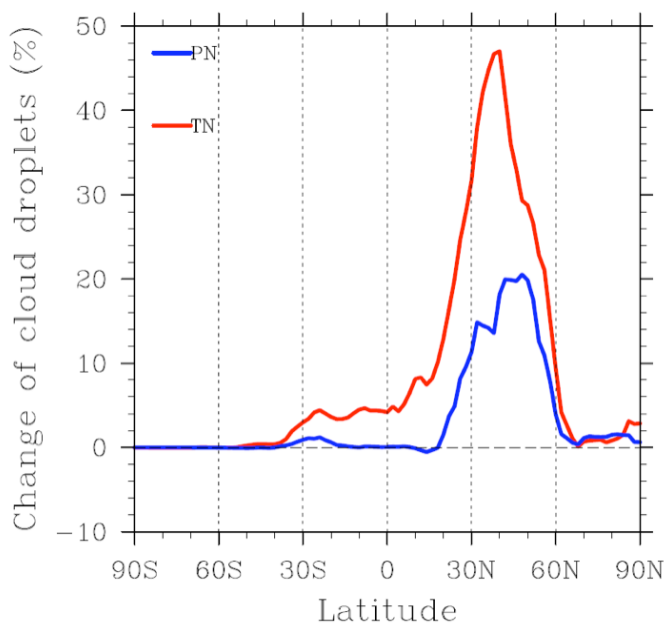

Fig. 14. The percentage change in zonal annual-average cloud droplet number for the case PN and the case TN compared to the $\mathrm{NN}$ case near $930 \mathrm{mb}$ (the third model layer).
South Africa. The added mass of soluble gases facilitates the activation of smaller particles by causing a lower critical super-saturation and a higher hygroscopicity. Figure 14 summarizes the percentage change in zonal annual-average cloud droplet number for the PN and TN cases with respect to the NN case near $930 \mathrm{mb}$. There is a large peak in the change of cloud droplets near $30^{\circ} \mathrm{N}$ and $60^{\circ} \mathrm{N}$ corresponding to the locations of the highest nitrate aerosol and nitric acid concentrations.

Figure 15 shows the spatial distribution of the change in droplet effect radius and the first aerosol indirect forcing for the TN case. The aerosol indirect forcing in this case is $-1.48 \mathrm{~W} \mathrm{~m}^{-2}$. The spatial distribution of the first indirect forcing is not only determined by the change in the cloud top effective radius but also by the cloud distribution. The maximum in the first aerosol indirect forcing occurs in the storm track region over the north Pacific. This is consistent with the pattern shown in Wang and Penner (2009). This peak is caused by both the strong decrease in the cloud droplet 

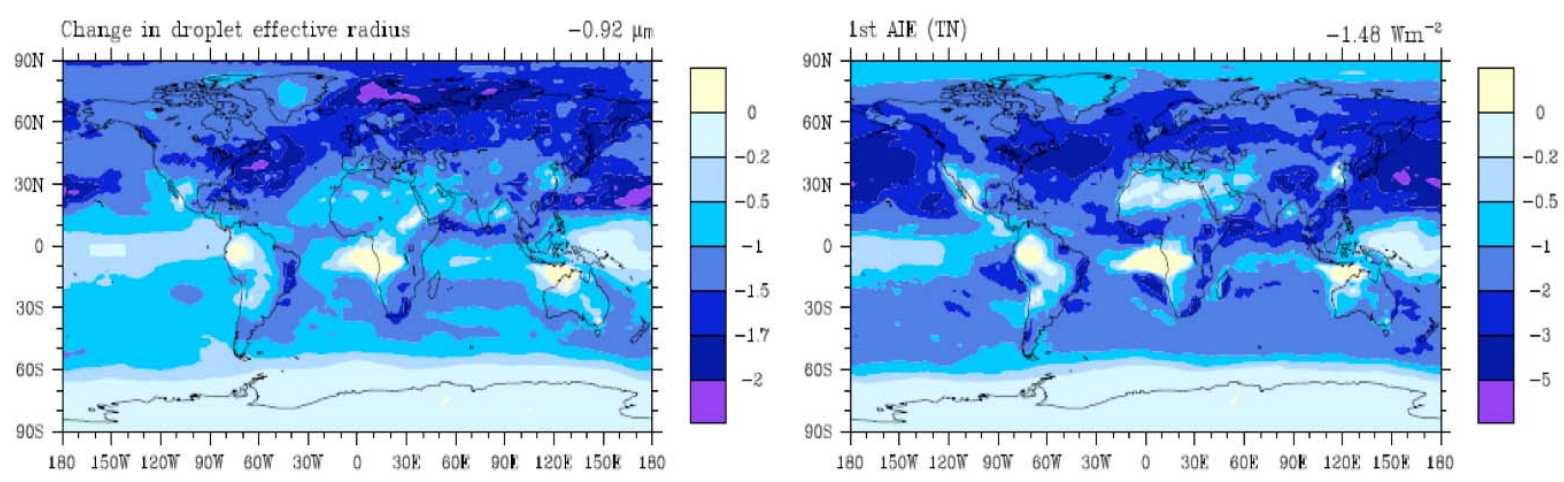

Fig. 15. The spatial distribution of the change in droplet effect radius (left) and the first aerosol indirect forcing between the PD and PI simulations (right) for the TN case.

Table 8. Global annual-average cloud droplet number concentration at cloud top in the PD (PI) simulation, cloud top effective radius in the PD (PI) simulation, cloud optical thickness in the PD (PI) simulation ${ }^{\mathrm{a}}$, absolute (percentage ${ }^{\mathrm{b}}$ ) change in cloud top droplet number concentration, cloud top effective radius and cloud optical thickness from anthropogenic emission, and 1st AIE for all three cases and the difference of the case $\mathrm{NN}$ and $\mathrm{TN}$ at the top of atmosphere.

\begin{tabular}{lrrrrrrr}
\hline Case & $N_{\mathrm{d}}\left(\# / \mathrm{cm}^{3}\right)$ & $R_{\mathrm{e}}(\mu \mathrm{m})$ & $\tau_{\mathrm{c}}$ & Change in $N_{\mathrm{d}}\left(\# / \mathrm{cm}^{3}\right)$ & Change in $R_{\mathrm{e}}(\mu \mathrm{m})$ & Change in $\tau_{\mathrm{c}}$ & $1 \mathrm{st}$ AIE $\left(\mathrm{W} \mathrm{m}^{-2}\right)$ \\
\hline $\mathrm{NN}$ & $112.47(74.03)$ & $10.44(11.32)$ & $29.85(27.34)$ & $38.44(51.92 \%)$ & $-0.88(-7.77 \%)$ & $2.51(9.18 \%)$ \\
$\mathrm{PN}$ & $115.11(71.29)$ & $10.43(11.31)$ & $29.89(27.36)$ & $43.82(61.47 \%)$ & $-0.88(-7.78 \%)$ & $2.53(9.25 \%)$ & -1.39 \\
TN & $125.38(74.75)$ & $10.31(11.23)$ & $30.15(27.51)$ & $50.63(67.73 \%)$ & $-0.92(-8.19 \%)$ & $2.64(9.60 \%)$ & -1.40 \\
$\mathrm{Net}^{\mathrm{c}}$ & & & & & & -1.48 \\
\hline
\end{tabular}

a The values outside and inside the parenthesis in column 2-4 represent the results from the PD and PI scenario.

$\mathrm{b}$ The percentage values inside the parenthesis in column 5-7 is calculated as the difference from the PI to the PD divided by the values in the PI scenario.

c "net" represents the first aerosol indirect forcing of anthropogenic $\mathrm{HNO}_{3}$ and nitrate and ammonium aerosol and the forcing due to anthropogenic $\mathrm{HNO}_{3}$ gas only (i.e., value insidethe parenthesis).

effective radius and the large cloud forcing over this region. Figure 16 shows the first aerosol indirect effect of total nitrate (gas plus aerosol) and ammonium (TN case minus NN case) for the PD (top), PI (middle) simulation and the PD$\mathrm{PI}$ anthropogenic indirect forcing of total nitrate and ammonium (bottom) at the TOA. The indirect effect of total nitrate and ammonium for the PD and PI simulations is estimated to be $-0.23 \mathrm{~W} \mathrm{~m}^{-2}$ and $-0.15 \mathrm{~W} \mathrm{~m}^{-2}$, which results in an anthropogenic indirect forcing of $-0.09 \mathrm{~W} \mathrm{~m}^{-2}$, equivalent to a $6 \%$ enhancement compared to the total first aerosol indirect forcing without nitrate and ammonium. The local effects of total nitrate and ammonium for the PD simulation is even larger, up to $-1.5 \sim-2 \mathrm{~W} \mathrm{~m}^{-2}$ over Europe, eastern Asia, eastern United States and the coastal area close to central Africa. Our present-day indirect effect of total nitrate and ammonium is only half that estimated for the present-day indirect effect of nitric acid gas by Makkonen et al. (2012) (i.e. $-0.23 \mathrm{~W} \mathrm{~m}^{-2}$ vs. $-0.32 \mathrm{~W} \mathrm{~m}^{-2}$ ). This large difference could result from the different parameterizations of the effect of nitric acid gas on aerosol activation (i.e. we used the substitution method of Chen, 2006 while Makkonen et al., 2012 used the parameterization of Romakkaniemi et al., 2005). But the simulated nitric acid mass concentrations between these two studies might also differ. It has been documented that there is factor of two or larger variation in the calculation of tropospheric $\mathrm{NO}_{2}$ column densities for different regions (i.e. Eastern US, Europe, East Asia, Africa, South America) (van Noije et al., 2006), although $\mathrm{HNO}_{3}$ variations might be smaller or larger than those for $\mathrm{NO}_{2}$. Since the study of Makkonen et al. (2012) did not provide a global budget and burden of nitric acid gas, we can not precisely understand the cause of the differences at this stage.

Table 8 gives a summary of global annual-average cloud droplet number concentration at the cloud top as deduced using the ISCCP cloud simulator similar as Wang and Penner (2009), cloud top effective radius, cloud optical thickness in the PD and PI (i.e. values in parentheses) simulations, and the absolute change and relative percentage change (i.e. values in parentheses) in cloud top droplet number concentration, cloud top effective radius and cloud optical thickness from anthropogenic emissions (i.e. PD-PI values). The last column provides the PD-PI 1st AIE for the NN, PN, and $\mathrm{TN}$ cases at the top of atmosphere. In general, the cloud top droplet number and cloud optical thickness increase from the NN case to the TN case for both the PD and PI scenarios while the cloud top effective radius decreases. The cloud top droplet number concentration for the NN, PN and TN cases increases by $52 \%, 61 \%$ and $68 \%$, respectively, between the 

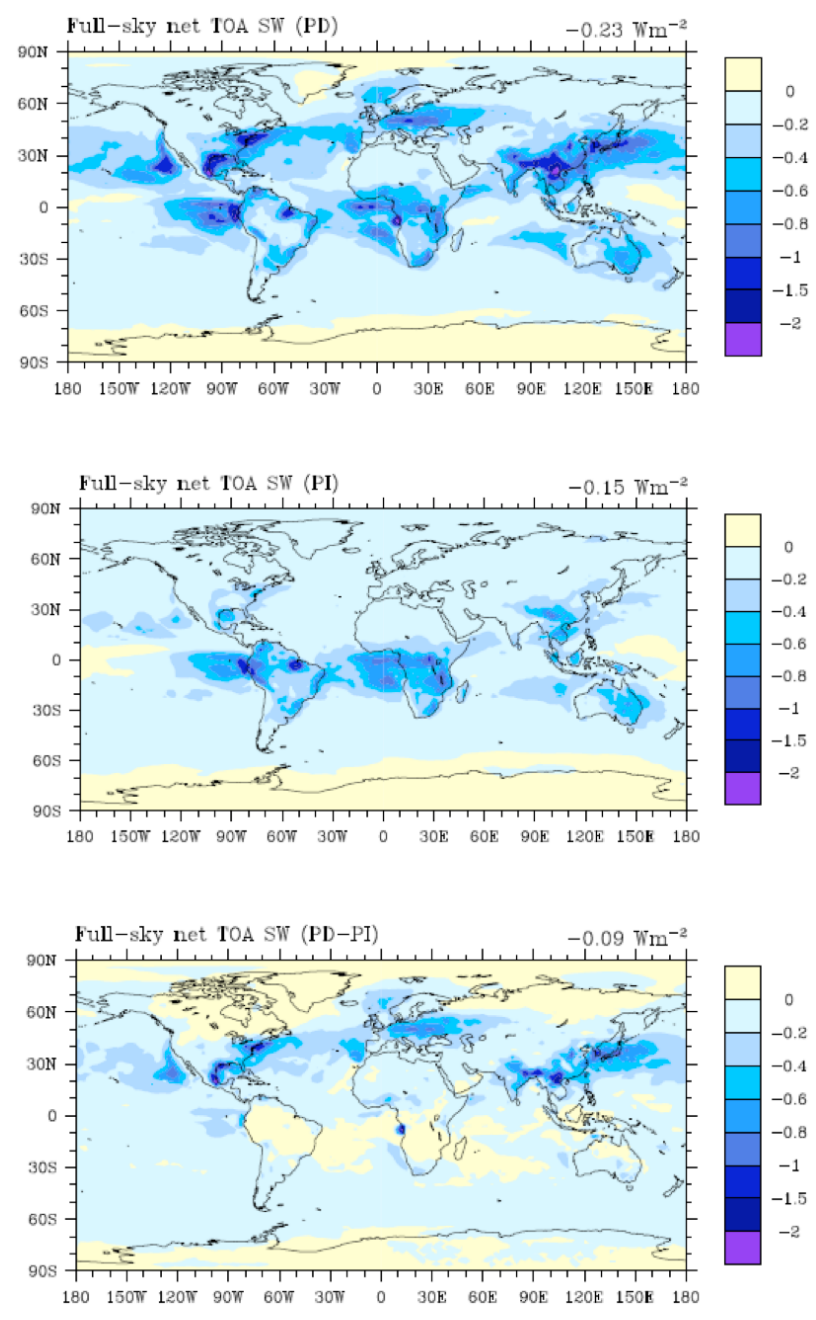

Fig. 16. The first aerosol indirect effect of total nitrate (gas plus aerosol) and ammonium for the PD (top), PI (middle) simulation and the PD - PI anthropogenic aerosol indirect forcing (bottom) at the top of atmosphere (TOA). The mean forcing value is indicated in each panel.

PD and PI simulations. The relative changes in cloud top effective radius and cloud optical depth are smaller, only about $8-10 \%$. The addition of total nitrate and ammonium contributes to the increase of cloud droplet number concentration by $16 \%$ (comparing the $\mathrm{NN}$ case and the TN case in the 5th column) while it only decreases the cloud top effective radius by $0.04 \mu \mathrm{m}$ (comparing the $\mathrm{NN}$ case and the $\mathrm{TN}$ case in the 6th column), equivalent to a $0.4 \%$ in the relative change consistent with the latter only scaling as the inverse of droplet number to the $1 / 3$ power. The total (gas plus aerosol) first aerosol indirect forcing of anthropogenic nitrate and ammonium is dominated by the nitric acid gas effect, which is $-0.08 \mathrm{~W} \mathrm{~m}^{-2}$ out of total $-0.09 \mathrm{~W} \mathrm{~m}^{-2}$ on a global average basis. Figure 17 shows the first aerosol indirect forcing of anthropogenic nitrate and ammonium over

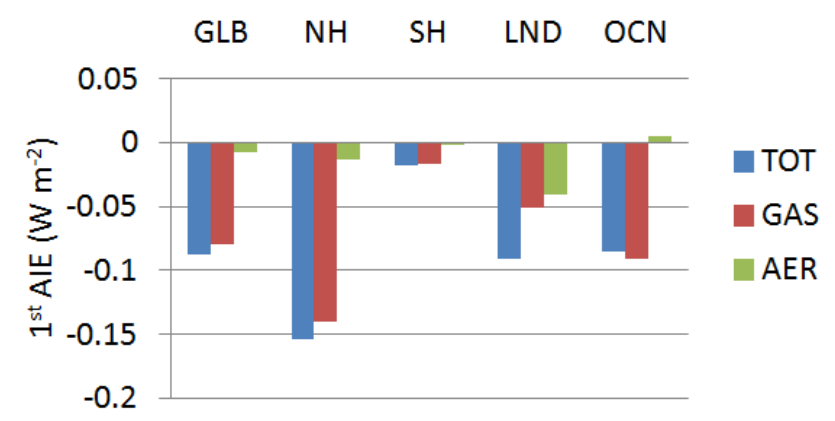

Fig. 17. The first aerosol indirect anthropogenic forcing at the top of atmosphere over five areas for the three cases (AER: PN-NN; GAS: TN-PN; TOT: TN-NN). GLB, NH, SH, LND and OCN stand for the global average, average over the Northern and Southern Hemisphere, average over the land and ocean, respectively.

5 areas to differentiate the forcing from $\mathrm{HNO}_{3}$ gas and particulate nitrate and ammonium. Anthropogenic total nitrate (gas plus aerosol) and ammonium aerosols have a higher influence on clouds in the Northern Hemisphere than in the Southern Hemisphere and higher effects over land than over the ocean. The aerosol nitrate and ammonium exert a higher influence over land than over the oceans, which is consistent with their larger concentrations over continents. In contrast, nitric acid gas exerts a higher influence over the ocean than over land, which is consistent with the significant effect of nitric acid gas in modifying clouds over the coastal regions close to continents (see Fig. 16). The large anthropogenic indirect forcing of nitric acid gas over the coastal regions is due to the amount of clouds seen in these regions together with the increase in the number of cloud droplets associated with sulfate, fossil fuel carbonaceous aerosols, and biomass burning aerosols when nitric acid gas is added (compare Figs. 12 and 13).

\section{Summary and discussion}

This work presents a global modeling study that simulates the heterogeneous formation of nitrate and ammonium by updating the previous model framework presented in Feng and Penner (2007). In this work, the University of Michigan version of the IMPACT aerosol model which includes sulfur dynamics (Liu et al., 2005) is used to generate the chemicaland size-resolved aerosol global distribution. We account for the interaction between nitric acid and ammonia with all five types of pre-existing aerosols (i.e. sulfate, carbonaceous aerosols from fossil fuel combustion, carbonaceous aerosols from biomass burning, dust and sea salt) which differs from the study by Feng and Penner (2007) who assumed that all aerosol components were internally mixed in each size bin. Our major goal was to explore the aerosol direct and indirect radiative forcing induced by $\mathrm{HNO}_{3}$ gas as well as aerosol ammonium and nitrate. For this purpose, two global simulations 

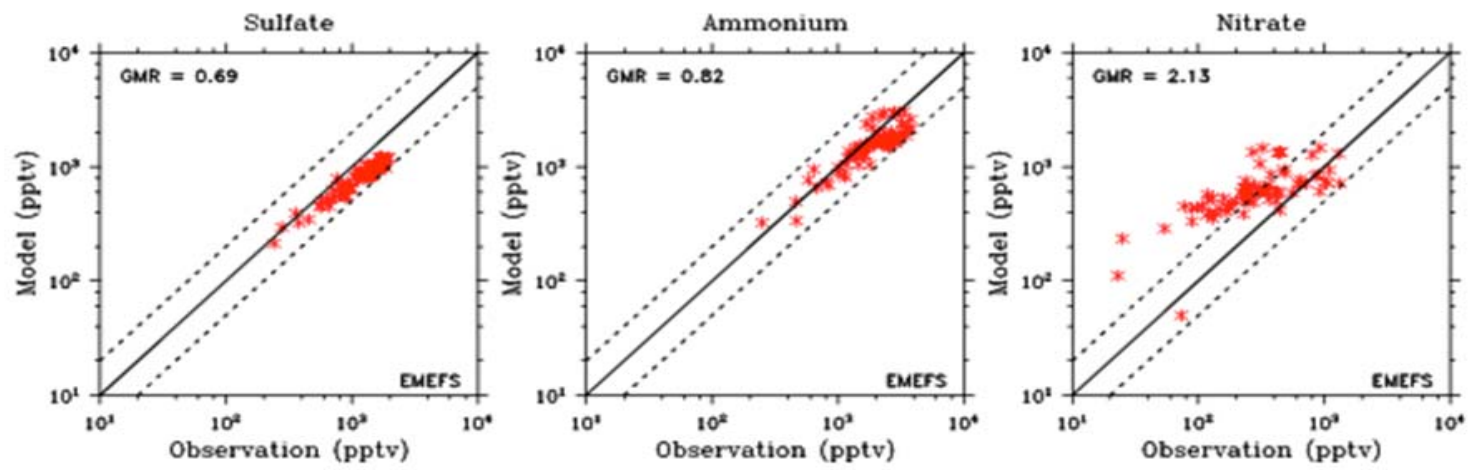

Fig. A1. Modeled and observed annual average concentrations for sulfate, ammonium and nitrate aerosols from the EMEFS (North America) network.
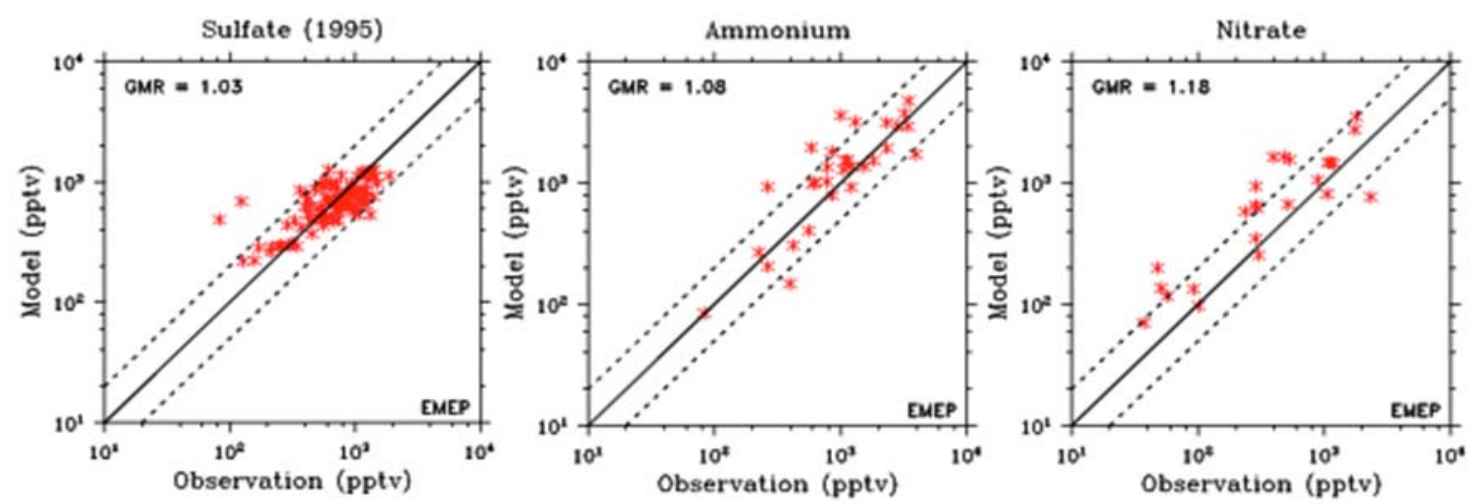

Fig. A2. Modeled and observed annual average concentrations for sulfate, ammonium and nitrate aerosols from the EMEP (Europe) network.

using the hybrid dynamic method with present day (PD) and preindustrial (PI) emissions were conducted. An offline- radiation transfer model was then used to assess both the direct and indirect forcing of $\mathrm{HNO}_{3}$, nitrate and ammonium using the PD and PI concentration fields.

The model developed here predicts a similar spatial distribution for total nitrate and ammonium as the pioneering studies (Feng and Penner, 2007; Liao et al., 2003; Adams et al., 1999) for the PD scenario. The predicted aerosol optical depth in the present day captures the general spatial pattern of AERONET-observed AOD (e.g. peaks in eastern Asia, Europe and the Sahara) but with smaller magnitude. The modeled AOD is underestimated, especially over the South America biomass burning region, which possibly indicates that the biomass burning emissions in this region are too low. The modeled single scattering albedo at $550 \mathrm{~nm}$ is in general agreement with observations but shows some underestimation over South America.

Nitrate and ammonium are found to exhibit two counteracting effects with respect to the direct effect of the preexisting (non nitrate and ammonium) aerosols in this work.
The inclusion of ammonium and nitrate can boost the scattering efficiency of scattering aerosols such as sulfate and biomass burning organic matter since ammonium nitrate is generally more hygroscopic than ammonium sulfate and organic matter in terms of the Kappa parameter (Petters and Kreidenweis, 2007) and this increases their size and hence their cooling effect. Additionally, nitrate and ammonium lowers the ability of sea salt aerosols to take up water due to the lower hygroscopicity of nitrate and ammonium than that of sea salt. The direct effect of nitrate and ammonium at the TOA for the present-day is estimated to be $-0.14 \mathrm{~W} \mathrm{~m}^{-2}$, within the range published for other models, but the more accurate methods used here place our result in contrast with these models. Smaller forcing is estimated for the PI scenario due to the smaller burden of ammonium and nitrate. The direct anthropogenic (PD-PI) forcing of nitrate and ammonium is estimated to be $-0.12 \mathrm{~W} \mathrm{~m}^{-2}$ at the TOA and $-0.16 \mathrm{~W} \mathrm{~m}^{-2}$ at the surface. The total global annual average direct anthropogenic forcing from all aerosol components is estimated to be $-0.3 \mathrm{~W} \mathrm{~m}^{-2}$, which is within the range of $-0.1 \sim-0.9 \mathrm{~W} \mathrm{~m}^{-2}$ reported in AR4 (Forster et al., 2007). 
The contribution of aerosol nitrate and ammonium to the total clear sky direct anthropogenic forcing is approximately $13 \%$ on a global basis, indicating that the nitrate and ammonium should not be ignored in the future assessment.

The indirect effect induced by total nitrate (gas and particle phase) and ammonium was also examined based on the parameterization proposed by Chen (2006). The first aerosol indirect effect of total nitrate and ammonium for the PD and PI simulation is estimated to be $-0.23 \mathrm{~W} \mathrm{~m}^{-2}$ and $-0.15 \mathrm{~W} \mathrm{~m}^{-2}$ at TOA, leading to a first aerosol indirect anthropogenic forcing of $-0.09 \mathrm{~W} \mathrm{~m}^{-2}$ at TOA induced by anthropogenic $\mathrm{HNO}_{3}$ gas, nitrate and ammonium. This is mainly determined by the nitric acid gas effect, which is $-0.08 \mathrm{~W} \mathrm{~m}^{-2}$ on a global basis with higher effects over oceans. This is the first estimate that we know of for the anthropogenic nitric acid gas indirect effect.

Acknowledgements. LX and JEP are grateful to the DOE Atmospheric Science Research Program (grant number DOEDE-FG02-97-ER62370) and to the DOE Climate Program (grant number DOE-FG02-01-ER63248) for partial support of this work. Some of this work took place while LX was supported as a student at the Max Planck Institute for Chemistry. LX and JEP thank X. Huang (University of Michigan) who provided useful comments on a draft of this paper. LX and JEP are grateful for S. Kinne (Max Planck Institute for Meteorology) who provided the observational data for aerosol optical properties derived from the AERONET.

Edited by: M. Kopacz

\section{References}

Abdul-Razzak, H. and Ghan, S. J.: A parameterization of aerosol activation - 3. Sectional representation, J. Geophys. Res., 107, 4026, doi:10.1029/2001JD000483, 2002.

Adams, P. J., Seinfeld, J. H., and Koch, D. M.: Global concentration of tropospheric sulphate, nitrate and ammonium aerosol simulated in a general circulation model, J. Geophys. Res., 104, 13791-13823, 1999.

Adams, P. J., Seinfeld, J. H., Koch, D. M, Mickley, L., and Jacob, D.: General circulation model assessment of direct radiative forcing by the sulphate-nitrate-ammonium-water inorganic aerosol system, J. Geophys. Res., 106, 1097-1111, 2001.

Anderson Jr., B. E., Sachse, G. W., Bagwell, D. R., Hudgins, C. H., Blake, D. R., and Blake, N. J.: Aerosols from biomass burning over the tropical South Atlantic region: Distributions and impacts, J. Geophys. Res., 101, 24117-24138, 1996.

Ansari, A. S. and S. N. Pandis: Response of inorganic PM to precursor concentrations, Environ. Sci. Technol., 32, 2706-2714, 1998.

Bauer, S. E., Koch, D., Unger, N., Metzger, S. M., Shindell, D. T., and Streets, D. G.: Nitrate aerosols today and in 2030: a global simulation including aerosols and tropospheric ozone, Atmos. Chem. Phys., 7, 5043-5059, doi:10.5194/acp-7-5043-2007, 2007.

Binkowski, F. S. and Shankar, U.: The regional particulate matter model, 1 . mode desription and preliminary results, J. Geophys. Res., 100, 26191-26209, 1995.
Bond, T. C., Habib, G., and Bergstrom, R. W.: Limitations in the enhancement of visible light absorption due to mixing state, J. Geophys. Res., 111, D20211, doi:10.1029/2006JD007315, 2006.

Bouwman, A. F., Lee, D. S., Asman, W. A. H., Dentener, F. J., Van Der Hoek, K. W., and Olivier, J. G. J.: A global high-resolution emission inventory for ammonia, Global Biogeochem. Cy., 11, 561-588, 1997.

Capaldo, K., Pilinis, C., and Pandis, S. N.: A computationally efficient hybrid approach for dynamic gas/aerosol transfer in air quality models, Atmos. Environ., 34, 3617-3627, 2000.

Chen, Y.: Aerosol indirect effects on clouds and global climate, $\mathrm{PhD}$, Department of Atmospheric, Oceanic, and Space Sciences, University of Michigan, Ann Arbor, MI, 218 pp., 2006.

Chen, Y. and Penner, J. E.: Uncertainty analysis for estimates of the first indirect aerosol effect, Atmos. Chem. Phys., 5, 2935-2948, doi:10.5194/acp-5-2935-2005, 2005.

Chuang, C. E., Ramanathan V., and Decremer, D.: Observationally constrained estimates of carbonaceous aerosol radiative forcing, P. Natl. Acad. Sci. USA, 109, 11624-11629, doi:10.1073/pnas.1203707109, 2012.

Dall'Osto, M., Harrison, R. M., Coe, H., Williams, P. I., and Allan, J. D.: Real time chemical characterization of local and regional nitrate aerosols, Atmos. Chem. Phys., 9, 3709-3720, doi:10.5194/acp-9-3709-2009, 2009.

d'Almeida, G. A., Koepke, P., and Shettle, E. P.: Atmospheric Aerosols: Global Climatology and Radiative Characteristics, A. Deepak, Hampton, Va, 1991.

Dassios, K. G. and Pandis, S. N.: The mass accommodation coefficient of ammonium nitrate aerosol, Atmos. Environ., 33, 29993003, 1999.

Ehhalt, D. and Drummond, J. W.: The tropospheric cycle of NOx: chemistry of the unpolluted and polluted troposphere, edited by: Georgii, W. J., Proc. NATO Adv. Study Inst.,Corfu, Greece, 28 September-10 Octtober 1981 Reidel, Dordrecht, 219-251, 1982.

Feng, Y. and Penner, J. E.: Global modeling of nitrate and ammonium: Interaction of aerosols and tropospheric chemistry, J. Geophys. Res., 112, D01304, doi:10.1029/2005JD006404, 2007.

Forster, P., Ramaswamy, V., Artaxo, P., Berntsen, T., Betts, R., Fahey, D. W., Haywood, J., Lean, J., Lowe, D. C., Myhre, G., Nganga, J., Prinn, R., Raga, G., Schulz, M., and Van Dorland, R.: Changes in Atmospheric Constituents and in Radiative Forcing, in: Climate Change 2007:The Physical Science Basis. Contribution of Working Group I to the Fourth Assessment Report of the Intergovernmental Panel on Climate Change, edited by: Solomon, S., Qin, D., Manning, M., Chen, Z., Marquis, M., Averyt, K. B., Tignor, M., and Miller, H. L., Cambridge University Press, Cambridge, United Kingdom and New York, NY, USA, 2007.

Ghan, S. J., Guzman, G., and Abdul-Razzak, H.: Competition between sea salt and sulfate particles as cloud condensation nuclei, J. Atmos. Sci., 55, 3340-3347, 1998.

Ghan, S., Laulainen, N., Easter, R., Wagener, R., Nemesure, S., Chapman, E., Zhang, Y., and Leung, R.: Evaluation of aerosol direct radiative forcing in MIRAGE, J. Geophys. Res., 106, 52955316, doi:10.1029/2000JD900502, 2001.

Ginoux, P., Chin, M., Tegen, I., Prospero, J. M., Holben, B., Dubovik, O., and Lin, S. J.: Sources and distributions of dust aerosols simulated with the GOCART model, J. Geophys. Res., 106, 20255-20273, 2001. 
Gong, S. L., Barrie, L. A., and Blanchet, J. P.: Modeling sea-salt aerosols in the atmosphere .1. Model development, J. Geophys. Res., 102, 3805-3818, 1997.

Goodman, A. L., Underwood, G. M., and Grassian, V. H.: A laboratory study of the heterogeneous reaction of nitric acid on calcium carbonate particles, J. Geophys. Res., 105, 29053-29064, 2000.

Haywood, J. M. and Shine, K. P.: The effect of anthropogenic sulfate and soot aerosol on the clear sky planetary radiation budget, Geophys. Res. Lett., 22, 603-606, 1995.

Heintzenberg, J., Wendisch, M., Yuskiewicz, B., Orsini, D., Wiedensohler, A., Stratmann, F., Frank, G. P., Martinsson, B. G., Schell, D., Fuzzi, S., and Orsi, G.: Characteristics of haze, mist and fog, Contrib. Atmos. Phys., 71, 21-31, 1998.

Herzog, M., Weisenstein, D. K., and Penner, J. E.: A dynamic aerosol module for global chemical transport models: Model description, J. Geophys. Res., 109, D18202, doi:10.1029/2003JD004405, 2004.

Intergovernmental Panel on Climate Change (IPCC), Climate change 1994: Radiative Forcing of Climate Change and an Evaluation of the IPCC IS92 Emission Scenarios, edited by: Houghton, J. T., Meria Filho, L. G., Bruce, J., Lee, H., Callander, B. A., Haites, E. F., Harris, N., and Maskell, K., Cambridge Univ. Press, Cambridge, United Kingdom and New York, NY, USA, 1994.

Ito, A. and Akimoto, H.: Seasonal and interannual variations in $\mathrm{CO}$ and $\mathrm{BC}$ emissions from open biomass burning in Southern Africa during 1998-2005, Global Biogeochem Cy., 21, GB2011, doi:10.1029/2006GB002848, 2007.

Ito, A., Sillman, S., and Penner, J. E.: Global chemical transport model study of ozone response to changes in chemical kinetics and biogenic volatile organic compounds emissions due to increasing temperatures: Sensitivities to isoprene nitrate chemistry and grid resolution, J. Geophys. Res., 114, D09301, doi:10.1029/2008JD011254, 2009.

Jacob, D. J. and Wofsy, S. C.: Budgets of reactive nitrogen, hydrocarbons, and ozone over the Amazon forest during the wet season, J. Geophys. Res., 95, 16737-16754, 1990.

Jacobson, M. Z.: Development and application of a new air pollution modeling system-II: Aerosol module structure and design, Atmos. Environ., 31A, 131-144, 1997a.

Jacobson, M. Z.: Numerical techniques to solve condensational and dissolutional growth equations when growth is coupled to reversible reactions, Aerosol Sci. Techinol., 27, 491-498, 1997b.

Jacobson, M. Z.: Studying the effects of calcium and magnesium on size-distributed nitrate and ammonium with EQUISOLV II, Atmos. Environ., 33, 3635-3649, 1999.

Jacobson, M. Z.: Global direct radiative forcing due to multicomponent anthropogenic and natural aerosols, J. Geophys. Res., 106, 1551-1568, 2001.

Jacobson, M. Z., Tabazadeh, A., and Turco, R.: Simulating equilibrium within aerosols and nonequilibrium between gases and aerosols, J. Geophys. Res., 101, 9079-9091, 1996.

Jayaraman, A., Lubin, D., Ramachandran, S., Ramanathan, V., Woodbridge, E., Collins, W. D., and Zalpuri, K. S.: Direct observations of aerosol radiative forcing over the tropical Indian Ocean during the January-February 1996 pre-INDOEX cruise, J. Geophys. Res., 103, 13827-13836, doi:10.1029/98JD00559, 1998.
Jimenez, J. L., Canagaratna, M. R., Donahue, N. M., et al.: Evolution of organic aerosols in the atmosphere, Science, 326, 15251529, doi:10.1126/science.1180353, 2009.

John, W., Wall, S. M., Ondo, J. L., and Winklmayr, W.: Acidicaerosol size distributions during SCAQS (Southern California Air Quality Study), final report, Rep. CA/DOH/AIHL/SP-51, Calif. Air Resour. Board, Sacramento, 1989.

Karydis, V. A., Kumar, P., Barahona, D., Sokolik,I. N., and Nenes, A.: On the effect of dust particles on global cloud condensation nuclei and cloud droplet number, J. Geophys. Res., 116, D23204, doi:10.1029/2011JD016283, 2011.

Kinne, S., Schulz, M., Textor, C., Guibert, S., Balkanski, Y., Bauer, S. E., Berntsen, T., Berglen, T. F., Boucher, O., Chin, M., Collins, W., Dentener, F., Diehl, T., Easter, R., Feichter, J., Fillmore, D., Ghan, S., Ginoux, P., Gong, S., Grini, A., Hendricks, J., Herzog, M., Horowitz, L., Isaksen, I., Iversen, T., Kirkevåg, A., Kloster, S., Koch, D., Kristjansson, J. E., Krol, M., Lauer, A., Lamarque, J. F., Lesins, G., Liu, X., Lohmann, U., Montanaro, V., Myhre, G., Penner, J., Pitari, G., Reddy, S., Seland, O., Stier, P., Takemura, T., and Tie, X.: An AeroCom initial assessment - optical properties in aerosol component modules of global models, Atmos. Chem. Phys., 6, 1815-1834, doi:10.5194/acp-6-1815-2006, 2006.

Kirchstetter, T. W., Novakov, T., and Hobbs, P. V.: Evidence that the spectral dependence of light absorption by aerosols is affected by organic carbon, J. Geophys. Res.-Atmos., 109, D21208, doi:10.1029/2004JD004999, 2004.

Kleeman, M. K., Cass, G. R., and Elderin, A.: Modeling the airborne particle complex as a source-oriented external mixture, J. Geophys. Res., 102, 21355-21372, 1997.

Kulmala, M., Laaksonen, A., Korhonen, P., Vesala, T., Ahonen, T., and Barrett, J. C.: The Effect of Atmospheric Nitric-Acid Vapor on Cloud Condensation Nucleus Activation, J. Geophys. Res.Atmos., 98, 22949-22958, 1993.

Kulmala, M., Toivonen, A., Mattila, T., and Korhonen, P.: Variations of cloud droplet concentrations and the optical properties of clouds due to changing hygroscopicity: A model study, J. Geophys. Res.-Atmos., 103, 16183-16195, 1998.

Lefer, B. L. and Talbot, R. W.: Summertime measurements of aerosol nitrate and ammonium at a northeastern U.S. site, J. Geophys. Res., 106, 20365-20378, doi:10.1029/2000JD900693, 2001.

Li, X., Larson, D. E., Gliberic, M., and Oaks, A.: Effects of nitrogen metabolites on the induction of maize nitrate reductase, Plant Physiol., 102, Supplement, 37, 1993.

Liao, H. and Seinfeld, J. H.: Global impacts of gas-phase chemistry aerosol interactions on direct radiative forcing by anthropogenic aerosols and ozone, J. Geophys. Res., 110, D18208, doi:10.1029/2005JD005907, 2005.

Liao, H., Adams, P. J., Chung, S. H., Seinfeld, J. H., Mickley, L. J., and Jacob, D. J.: Interactions between tropospheric chemistry and aerosols in a unified general circulation model, J. Geophys. Res., 108, 4001, doi:10.1029/2001JD001260, 2003.

Liao, H., Seinfeld, J. H., Adams, P. J., and Mickley, L. J.: Global radiative forcing of coupled tropospheric ozone and aerosols in a unified general circulation model, J. Geophys. Res., 109, D16207, doi:10.1029/2003JD004456, 2004. 
Liao, H., Chen, W.-T., and Seinfeld, J. H.: Role of climate change in global predictions of future tropospheric ozone and aerosols, J. Geophys. Res., 111, D12304, doi:10.1029/2005JD006852, 2006.

Lin, G., Penner, J. E., Sillman, S., Taraborrelli, D., and Lelieveld, J.: Global modeling of SOA formation from dicarbonyls, epoxides, organic nitrates and peroxides, Atmos. Chem. Phys., 12, 47434774, doi:10.5194/acp-12-4743-2012, 2012.

Lin, S.-J. and R. B. Rood: Multidimensional flux-form semiLagrangian transport schemes, Mon. Weather Rev., 124, 20462070, 1996.

Liu, H. Y., Jacob, D. J., Bey, I., and Yantosca, R. M.: Constraints from pb-210 and be-7 on wet deposition and transport in a global three-dimensional chemical tracer model driven by assimilated meteorological fields, J. Geophys. Res., 106, 1210912128, 2001.

Liu, X. H., Penner, J. E., and Herzog, M.: Global modeling of aerosol dynamics: Model description, evaluation, and interactions between sulfate and nonsulfate aerosols, J. Geophys. Res., 110, D18206, doi:10.1029/2004JD005674, 2005.

Liu, X., Penner, J., Ghan, S., and Wang, M.: Inclusion of ice microphysics in the NCAR Community Atmospheric Model Verision 3 (CAM3), J. Clim., 20, 4526-4547, 2007.

Lurmann, F. W., Wexler, A. S., Pandis, S. N., Musarra, S., Kumar, N., and Seinfeld, J. H.: Modeling urban and regional aerosols, Atmos. Environ., 31A, 2695-2715, 1997.

Makkonen, R., Romakkaniemi, S., Kokkola, H., Stier, P., Räisänen, P., Rast, S., Feichter, J., Kulmala, M., and Laaksonen, A.: Brightening of the global cloud field by nitric acid and the associated radiative forcing, Atmos. Chem. Phys., 12, 7625-7633, doi:10.5194/acp-12-7625-2012, 2012.

Malm, W. C., Schichtel, B. A., Pitchford, M. L., Ashbaugh, L. L., and Eldred, R. A.: Spatial and monthly trends in speciated fine particle concentration in the United States, J. Geophys. Res., 109, D03306, doi:10.1029/2003JD003739, 2004.

Mari, C., Jacob, D. J., and Bechtold, P.: Transport and scavenging of soluble gases in a deep convective cloud, J. Geophys. Res., 105, 22255-22267, 2000.

Meng, Z. and Seinfeld, J. H.: Time Scales to Achieve Atmospheric Gas-Aerosol Equilibrium for Volatile Species, Atmos. Environ., 30, 2889-2900, 1996.

Meng, Z., Dabdub, D., and Seinfeld, J. H.: Size-resolved and chemically resolved model of atmospheric aerosol dynamics, J. Geophys. Res., 103, 3419-3435, 1998.

Merikanto, J., Spracklen, D. V., Pringle, K. J., and Carslaw, K. S.: Effects of boundary layer particle formation on cloud droplet number and changes in cloud albedo from 1850 to 2000, Atmos. Chem. Phys., 10, 695-705, doi:10.5194/acp-10-695-2010, 2010.

Metzger, S., Dentener, F., Krol, M., Jeuken, A., and Lelieveld, J.: Gas/aerosol partitioning: 2. Global modeling results, J. Geophys. Res., 107, 4313, doi:10.1029/2001JD001103, 2002.

Monahan, E. C., Spiel, D. E., and Davidson, K. L.: A model of marine aerosol generation via whitecaps and wave disruption, in: Oceanic Whitecaps and Their Role in Air-Sea Exchange, edited by: Monahan, E. C. and MacNiocail, G., 167-174, Springer, New York, 1986.

Myhre G.: Consistency Between Satellite-Derived and Modeled Estimates of the Direct Aerosol Effect, Science, 325, 187, doi:10.1126/science.1174461, 2009.
Myhre, G., Berglen, T. F., Johnsrud, M., Hoyle, C. R., Berntsen, T. K., Christopher, S. A., Fahey, D. W., Isaksen, I. S. A., Jones, T. A., Kahn, R. A., Loeb, N., Quinn, P., Remer, L., Schwarz, J. P., and Yttri, K. E.: Modelled radiative forcing of the direct aerosol effect with multi-observation evaluation, Atmos. Chem. Phys., 9, 1365-1392, doi:10.5194/acp-9-1365-2009, 2009.

Pakkanen, T. A., Hillamo, R. E., Aurela, M., Andersen, H. V., Grundahl, L., Ferm, M., Persson, K., Karlsson, V., Reissell, A., Røyset, O., Fløisand, I., and Oyola, P.: Nordic intercomparison for measurement of major atmospheric nitrogen species, J. Aerosol Sci., 30, 247-263, 1999.

Parrish, D., Norton,R., Bollinger, M., Liu, S., Murphy, P., Albritton, D., and Fehsenfeld, F.: Measurements of' $\mathrm{HNO}_{3}$ and $\mathrm{NO}_{3}^{-}$particulates at a rural site in the Colorado mountains, J. Geophys. Res., 91, 5379-5393, 1986.

Penner, J. E., Atherton, C. A., and Graedel, T. E.: Global emissions and models of photochemically active compounds, in: Global Atmospheric-Biospheric Chemistry, edited by: Prinn, R., 223248, Springer, New York, 1994.

Penner, J. E., Chuang, C. C., and Grant, K.: Climate forcing by carbonaceous and sulfate aerosols, Clim. Dyn., 14, 839-851, 1998.

Penner, J. E., Andreae, M., Annegarn, H., Barrie, L., Feichter, J., Hegg, D., Jayaraman, A., Leaitch, R., Murphy, D., Nganga, J., and Pitari, G.: Aerosols, their direct and indirect effects, in: Climate Change 2001: The Scientific Basis, edited by: Houghton, J. T., Ding, Y., Griggs, D. J., Noguer, M., Van der Linden, P. J., Dai, X., Maskell, K., and Johnson, C. A., Cambridge Univ. Press, 289-348, 2001.

Petters, M. D. and Kreidenweis, S. M.: A single parameter representation of hygroscopic growth and cloud condensation nucleus activity, Atmos. Chem. Phys., 7, 1961-1971, doi:10.5194/acp-71961-2007, 2007.

Pilinis, C. and Seinfeld, J.H.: Continued development of a general equilibrium model for inorganic multicomponent atmospheric aerosols, Atmos. Environ., 32, 2453-2466, 1987.

Pilinis, C., Capaldo, K. P., Nenes, A., and Pandis, S. N.: MADMA new multicomponent aerosol dynamics model, Aerosol Sci. Technol., 32, 482, 2000.

Pringle, K. J., Tost, H., Message, S., Steil, B., Giannadaki, D., Nenes, A., Fountoukis, C., Stier, P., Vignati, E., and Lelieveld, J.: Description and evaluation of GMXe: a new aerosol submodel for global simulations (v1), Geosci. Model Dev., 3, 391-412, doi:10.5194/gmd-3-391-2010, 2010.

Putaud, J., van Dingenen, R., Baltensperger, U., Bruggemann, E., Charron, A., Facchini, M., Decesari, S., Fuzzi, S., Gehrig, R., Hansson, H.-C., Harrison, R. M., Jones, A. M., Laj, P., Lorbeer, G., Maen-haut, W., Mihalopoulos, N., Müller, K., Palmgren, F., Querol, X., Rodriguez, S., Schneider, J., Spindler, G., ten Brink, H., Tunved, P., Torseth, K.,Wehner, B.,Weingartner, E., Wiedensohler, A., Wahlin, P., and Raes, F.: A European aerosol phenomenology; physical and chemical characteristics of particulate matter at kerbside, urban, rural and background sites in Europe, European Commission, Report nr. EUR 20411 EN, 2003.

Quinn, P. K. and Coffman, D. J.: Local closure during the First Aerosol Characterization Experiment (ACE 1): Aerosol mass concentration and scattering and backscattering coefficients, J. Geophys. Res., 103, 16575-16596, 1998.

Radke, L. F., Hegg, D. A., Lyons, J. H., Brock, C. A., Hobbs, P. V., Weiss, R., and Rasmussen, R.: Airborne measurements on 
smokes from biomass burning, in: Aerosols and Climate, edited by: Hobbs, P. V. and McCormick, M. P., 411-422, A Deepak, Hampton, Va, 1988.

Rodriguez, M. A. and Dabdub, D.: IMAGES-SCAPE2: A modeling study of size- and chemically resolved aerosol thermodynamics in a global chemical transport model, J. Geophys. Res., 109, D02203, doi:10.1029/2003JD003639, 2004.

Romakkaniemi, S., Kokkola, H., and Laaksonen, A.: Parameterization of the nitric acid effect on CCN activation, Atmos. Chem. Phys., 5, 879-885, doi:10.5194/acp-5-879-2005, 2005.

Russell, A. G., McCue, K. F., and Cass, G. R.: Mathematical modeling of the formation of nitrogen-containing air pollutants. 1. Evaluation of an Eulerian photochemical model, Environ. Sci. Technol., 22, 263-271, 1988.

Savoie, D. L. and Prospero, J. M.: Particle size distribution of nitrate and sulfate in the marine atmosphere, Geophys. Res. Lett., 9, 1207-1210, doi:10.1029/GL009i010p01207, 1982.

Schaap, M., van Loon, M., ten Brink, H. M., Dentener, F. J., and Builtjes, P. J. H.: Secondary inorganic aerosol simulations for Europe with special attention to nitrate, Atmos. Chem. Phys., 4, 857-874, doi:10.5194/acp-4-857-2004, 2004.

Schulz, M., Textor, C., Kinne, S., Balkanski, Y., Bauer, S., Berntsen, T., Berglen, T., Boucher, O., Dentener, F., Guibert, S., Isaksen, I. S. A., Iversen, T., Koch, D., Kirkevåg, A., Liu, X., Montanaro, V., Myhre, G., Penner, J. E., Pitari, G., Reddy, S., Seland, $\varnothing$., Stier, P., and Takemura, T.: Radiative forcing by aerosols as derived from the AeroCom present-day and pre-industrial simulations, Atmos. Chem. Phys., 6, 5225-5246, doi:10.5194/acp-65225-2006, 2006.

Schwarz, J. P., Spackman, J. R., Gao, R. S., Watts, L. A., Stier, P., Schulz, M., Davis, S. M., Wofsy, S. C., and Fahey, D. W.: Global-scale black carbon profiles observed in the remote atmosphere and compared to models, Geophys. Res. Lett., 37, L18812, doi:10.1029/2010GL044372, 2010.

Seinfeld, J. H. and Pandis, S. N.: Atmospheric Chemistry and Physics: From Air Pollution to Climate Change, John, Wiley \& Sons, Inc., 1998.

Sun, Q. and Wexler, A. S.: Modeling urban and regional aerosols near acid neutrality application to the 24-25 June SCAQS episode, Atmos. Environ., 32, 3533-3545, 1998a.

Sun, Q. and Wexler, A. S.: Modeling urban and regional aerosolcondensation and evaporation near acid neutrality, Atmos. Environ., 32, 3527-3531, 1998b.

ten Brink, H. M., Veefkind, J. P., Waijers-Ijpelaan, A., and van der Hage, J. C.: Aerosol light-scattering in the Netherlands, Atmos. Environ., 30, 4251-4261, 1996.

ten Brink, H. M., Kruisz, C., Kos, G. P. A., and Berner, A.: Composition/size of the light-scattering aerosol in the Netherlands, Atmos. Environ., 31, 3955-3962, 1997.

Textor, C., Schulz, M., Guibert, S., Kinne, S., Balkanski, Y., Bauer, S., Berntsen, T., Berglen, T., Boucher, O., Chin, M., Dentener, F., Diehl, T., Easter, R., Feichter, H., Fillmore, D., Ghan, S., Ginoux, P., Gong, S., Grini, A., Hendricks, J., Horowitz, L., Huang, P., Isaksen, I., Iversen, I., Kloster, S., Koch, D., Kirkevåg, A., Kristjansson, J. E., Krol, M., Lauer, A., Lamarque, J. F., Liu, X., Montanaro, V., Myhre, G., Penner, J., Pitari, G., Reddy, S., Seland, $\varnothing .$, Stier, P., Takemura, T., and Tie, X.: Analysis and quantification of the diversities of aerosol life cycles within AeroCom, Atmos. Chem. Phys., 6, 1777-1813, doi:10.5194/acp-6-1777-2006,
2006.

Trebs, I., Metzger, S., Meixner, F., Helas, G., Hoffer, A., Rudich, Y., Falkovich, A., Moura, M., Da Silva, R., Artaxo, P., Slanina, J., and Andreae, M.: The $\mathrm{NH}_{4}+-\mathrm{NO}_{3}-\mathrm{Cl}-\mathrm{SO} 42-$ $\mathrm{H} 2 \mathrm{O}$ aerosol system and its gas phase precursors at a pasture site in the Amazon Basin: How relevant are mineral cations and soluble organic acids?, J. Geophys. Res., 110, D07303, doi:10.1029/2004JD005478, 2005.

van Aardenne, J. A., Dentener, F. J., Olivier, J. G. J., Klein Goldewijk, C. G. M., and Lelieveld, J.: A $1 \times 1$ degree resolution dataset of historical anthropogenic trace gas emissions for the period 1890-1990. Global Biogeochem. Cy., 15, 909-928, 2001. van Dorland, R., Dentener, F. J., and Lelieveld, J.: Radiative forcing due to tropospheric ozone and sulphate aerosols, J. Geophys. Res., 102, 28079-28100, 1997.

van Noije, T. P. C., Eskes, H. J., Dentener, F. J., Stevenson, D. S., Ellingsen, K., Schultz, M. G., Wild, O., Amann, M., Atherton, C. S., Bergmann, D. J., Bey, I., Boersma, K. F., Butler, T., Cofala, J., Drevet, J., Fiore, A. M., Gauss, M., Hauglustaine, D. A., Horowitz, L. W., Isaksen, I. S. A., Krol, M. C., Lamarque, J.-F., Lawrence, M. G., Martin, R. V., Montanaro, V., Müller, J.F., Pitari, G., Prather, M. J., Pyle, J. A., Richter, A., Rodriguez, J. M., Savage, N. H., Strahan, S. E., Sudo, K., Szopa, S., and van Roozendael, M.: Multi-model ensemble simulations of tropospheric $\mathrm{NO}_{2}$ compared with GOME retrievals for the year 2000, Atmos. Chem. Phys., 6, 2943-2979, doi:10.5194/acp-62943-2006, 2006.

Vehkamäki, H., Kulmala, M., Napari, I., Lehtinen, K. E. J., Timmreck, C., Noppel, M., and Laaksonen, A.: An improved parameterization for sulfuric acid-water nucleation rates for tropospheric and stratospheric conditions, J. Geophys. Res., 107, 4622, doi:10.1029/2002JD002184, 2002.

Walcek, C. J., Brost, R. A., and Chang, J. S.: $\mathrm{SO}_{2}$, sulfate and $\mathrm{HNO}_{3}$ deposition velocities computed using regional land use and meteorological data, Atmos. Environ., 20, 949-964, 1996.

Walton, J. J., Maccracken, M. C., and Ghan, S. J.: A global-scale lagrangian trace species model of transport, transformation, and removal processes, J. Geophys. Res., 93, 8339-8354, 1988.

Wang, M. and Penner, J. E.: Aerosol indirect forcing in a global model with particle nucleation, Atmos. Chem. Phys., 9, 239-260, doi:10.5194/acp-9-239-2009, 2009.

Wang, M., Penner, J. E., and Liu, X.: Coupled IMPACT aerosol and NCAR CAM3 model: Evaluation of predicted aerosol number and size distribution, J. Geophys. Res., 114, D06302, doi:10.1029/2008JD010459, 2009.

Wesely, M. L.: Parameterization of surface resistances to gaseous dry deposition in regional-scale numerical models, Atmos. Environ., 23, 1293-1304, 1989.

Wexler, A. S. and Seinfeld, J. H.: The distribution of ammonium salts among a size and composition dispersed aerosol, Atmos. Environ., 24A, 1231-1246, 1990.

Wolff, G. T.: On the nature of nitrate in coarse continental aerosols, Atmos. Environ., 18, 977-987, 1984.

Xu, L.: Global simulation of nitrate and ammonium aerosols and their radiative effects and comparison of satellite-based and modeled aerosol indirect forcing, Ph.D. thesis, Department of Atmospheric, Oceanic and Space Sciences, University of Michigan, Ann Arbor, 306 pp., 2012. 
Zhang, D., Iwasaka, Y., Shi, G., Zang, J., Matsuki, A., and Trochkine, D.: Mixture state and size of Asian dust particles collected at southwestern Japan in spring 2000, J. Geophys. Res., 108, 4760, doi:10.1029/2003JD003869, 2003.

Zhang, L., Gong, S. L., Padro, J., and Barrie, L.: A size-segregated particle dry deposition scheme for an atmospheric aerosol module, Atmos. Environ., 35, 549-560, 2001.
Zhang, S., Penner, J. E., and Torres, O.: Inverse modeling of biomass burning emissions using total ozone mapping spectrometer aerosol index for 1997, J. Geophys. Res., 110, D21306, doi:10.1029/2004JD005738, 2005. 